\title{
Dysregulation of germinal centres in autoimmune disease
}

\section{Carola G. Vinuesa*, Iñaki Sanz ${ }^{\ddagger}$ and Matthew C. Cook*§}

Abstract | In germinal centres, somatic hypermutation and B cell selection increase antibody affinity and specificity for the immunizing antigen, but the generation of autoreactive $B$ cells is an inevitable by-product of this process. Here, we review the evidence that aberrant selection of these autoreactive B cells can arise from abnormalities in each of the germinal centre cellular constituents - B cells, T follicular helper cells, follicular dendritic cells and tingible body macrophages - or in the supply of antigen. As the progeny of germinal centre B cells includes long-lived plasma cells, selection of autoreactive B cells can propagate long-lived autoantibody responses and cause autoimmune diseases. Elucidation of crucial molecular signals in germinal centres has led to the identification of novel therapeutic targets.

Autoantibody Antibody directed against an organism's own tissues.

Antinuclear antibodies (ANAs). Heterogeneous autoantibodies against one or more antigens present in the nucleus, including chromatin, nucleosomes and ribonuclear proteins. ANAs are found in association with many different autoimmune diseases.

* John Curtin School of Medical Research, Australian National University, GPO Box 334, Canberra, ACT 2601, Australia. ${ }^{\ddagger}$ University of Rochester Medical Center, School of Medicine and Dentistry, Rochester, New York 14627, USA.

${ }^{\S}$ Australian National University Medical School and The Canberra Hospital, Canberra, ACT 2605,

Australia.

Correspondence to C.G.V. e-mail: carola.vinuesa@anu.edu.au doi: 10.1038/nri2637
Activation of polyclonal B cells with lipopolysaccharide (LPS) showed that B cells with the potential to produce autoantibodies, including antinuclear antibodies (ANAs), are common in the normal $\mathrm{B}$ cell repertoire ${ }^{1,2}$. However, these autoantibodies are, for the most part, crossreactive, low-affinity IgM antibodies ${ }^{3}$ that have a bias towards binding to soluble rather than cell surface self antigens $s^{4}$. By contrast, most pathological autoantibodies bind antigen with high affinity, are IgG antibodies and contain mutations that are selected by antigen ${ }^{5-7}$. These are features of antibodies that are raised against typical protein antigens and are the products of plasma cells generated from germinal centres (GCs).

There are two phases of $\mathrm{T}$ cell-dependent $\mathrm{B}$ cell activation: the first phase occurs in foci formed at the outer $\mathrm{T}$ cell zone, which can give rise to short-lived plasma cells that accumulate in extrafollicular foci or induce $B$ cells that then enter the follicles to form GCs. The second phase occurs in GCs and results in the generation of affinity-matured long-lived plasma cells and memory B cells. ${ }^{8}$. In 1986 MacLennan and Gray proposed what became the standard model of $\mathrm{GCs}^{9}$ to account for several lines of evidence describing their function. According to this model, GC B cells undergo substantial antigendependent proliferation ${ }^{10}$ (and are termed centroblasts) and undergo a high rate of mutation in immunoglobulin variable $(\mathrm{V})$ region genes through a process known as somatic hypermutation (SHM) $)^{11,12}$. Antigen is captured by resident stromal cells known as follicular dendritic cells (FDCs) in a complement- and antibody-dependent process, and B cells are selected based on their affinity for the captured antigen. It was suggested that this was the probable role of GCs in the induction of memory $\mathrm{B}$ cells ${ }^{10}$. Immunoglobulin class switching is initiated during the first phase of $B$ cell activation, soon after the first $\mathrm{B}$ cell- $\mathrm{T}$ cell interaction in the outer $\mathrm{T}$ cell zone $^{13}$, but further switching can still occur within GCs. It is therefore not surprising to find significant rates of class switching in both follicular and extrafollicular responses.

Experimental manipulations, such as administering adjuvant and high concentrations of antigen, showed that affinity maturation can take place in the absence of $\mathrm{GCs}^{14}$. Although GCs may not be an absolute requirement for affinity maturation, the selective advantage conferred by these highly specialized, transient structures might be as an adaptation that simultaneously supports a complex mechanism of cellular amplification and selection in response to physiological concentrations and forms of antigen ${ }^{15}$ and limits the consequent risk of autoreactivity. The stochastic nature of SHM makes the generation of autoreactive $\mathrm{B}$ cell clones an almost certain by-product of $\mathrm{GCs}^{16,17}$. If these autoreactive $\mathrm{B}$ cells are not eliminated, there can be long-term consequences because plasma cells and memory B cells that are generated in GCs can live for many years ${ }^{18}$.

More than 80 distinct autoimmune diseases have been described and many of these are associated with the development of autoantibodies (see Supplementary information S1 (table)). Indeed, detection of autoantibodies in patients' serum is used in the clinical diagnosis of many autoimmune diseases. Some antibodies are specifically associated with a particular disease, whereas others are present in more than one autoimmune disease and even in apparently healthy individuals. Curiously, 


\author{
Centroblast \\ A proliferating germinal centre \\ $B$ cell with rearranged \\ variable-region \\ immunoglobulin genes that are \\ undergoing somatic \\ hypermutation \\ Somatic hypermutation \\ (SHM). A programmed process \\ of mutation targeting the \\ variable regions of \\ immunoglobulin genes that \\ allows the selection of $\mathrm{B}$ cells \\ that express immunoglobulin \\ receptors with highest affinity \\ for foreign antigens.
}

Immunoglobulin class switching (also known as class switch recombination (CSR)) A process that changes the constant region portion of the antibody heavy chain from one class (that is, IgM, IgD, IgG or (gA) to another, enabling the antibody to perform different effector functions and leaving the variable region of the heavy chain - and thus antigen specificity - unchanged.

T follicular helper $\left(\mathrm{T}_{\mathrm{FH}}\right)$ cell A type of helper $T$ cell that differentiates on $\mathrm{BCL}-6$ expression, localizes to follicles owing to high expression of CXCR5 and CXCR 4 and provides CD40L- and IL-21-mediated selection and survival signals to germina centre B cells.

\section{Centrocyte}

The non-dividing progeny of a centroblast. These cells need to be selected on the basis of their affinity for antigen, following interaction with immune complexes that are associated with follicular dendritic cells, and their ability to elicit help from $\mathrm{T}_{\mathrm{FH}}$ cells.

Complementaritydetermining regions

A short amino acid sequence found in the variable domains of antigen receptor proteins that complements an antigen and therefore provides the receptor with its specificity for that particular antigen the antigens that are recognized by autoantibodies have a range of expression patterns, from tissue-specific to ubiquitous, but tissue-specific pathology does not necessarily predict that the associated autoantibodies will be directed at antigens that are confined to the site of pathology. The specificity for disease, positive correlation between serum titre and disease activity, deposition of immune complexes in sites of end-organ pathology and recapitulation of diseases with serum transfer imply a pathogenic role for certain autoantibodies ${ }^{19}$ (Supplementary information S1 (table)).

Analysis of autoantibodies suggested that they share a common ontogeny with conventional antibodies that are formed during $\mathrm{T}$ cell-dependent responses to foreign antigens or indeed as a consequence of SHM in GCs ${ }^{20,21}$. One interpretation of autoantigen specificity is that they are antigen-driven. The combination of high antigen specificity, conferred by affinity maturation of an antibody, and the chronic nature of the autoantibody response suggests that many autoantibodies are the products of long-lived plasma cells, the ontogeny of which involves GCs. Recent studies that are discussed in this Review have provided experimental evidence that dysregulated GCs contribute to autoimmunity.

There is also abundant and convincing evidence that, like their non-autoimmune counterparts, autoantibodies can be generated extrafollicularly, either in the context of $\mathrm{T}$ cell-dependent or $\mathrm{T}$ cell-independent response ${ }^{22-27}$; in some models these autoantibodies are also somatically mutated ${ }^{23}$. Furthermore, we anticipate that, at least in some patients, autoimmune diseases may prove to be the result of combined dysregulated follicular and extrafollicular antibody production, but confirming this will depend on new approaches that can more accurately determine the origin of autoreactive plasma cells. This caveat notwithstanding, we focus our discussion here on the contribution of the GC pathway to autoimmune disease. We outline evidence for abnormal GC responses in autoimmune disease, including evidence that the complexity of GC development is recapitulated during inflammatory responses in non-lymphoid parenchyma, which complements the molecular evidence for antigen-mediated selection. Finally, we discuss progress in understanding the mechanisms of human disease and the possibilities for therapeutic intervention.

\section{GC biology}

$B$ and $T$ cell recruitment. The formation of GCs depends on intrafollicular localization of antigen, activated B cells and T cells. B cell activation is initially triggered by acute ligation with sufficient (suprathreshold) antigen, and results in the upregulation of CC-chemokine receptor 7 (CCR7) expression and migration of the $\mathrm{B}$ cells to the outer T cell zone. Here, B cells receive help from primed $\mathrm{T}$ helper $\left(\mathrm{T}_{\mathrm{H}}\right)$ cells. It has been proposed these $\mathrm{T}_{\mathrm{H}}$ cells are specialized CXC-chemokine receptor 5 (CXCR5) ${ }^{+}$ $\mathrm{T}$ cells - pre-T follicular helper cells - capable of secreting different cytokines ${ }^{28}$. Alternatively it is possible that nascent $T_{H} 1, T_{H} 2$ or $T_{H} 17$ cells can differentiate to become $\mathrm{T}$ follicular helper $\left(\mathrm{T}_{\mathrm{FH}}\right)$ cells after interacting with B cells or can complete differentiation to become bona fide effector $T_{H} 1, T_{H} 2$ and $T_{H} 17$ cells. After receiving $T$ cell help in the outer T cell zone, B cells either seed follicles, and potentially propagate GCs, or form extrafollicular plasma cell responses (TABLE 1). The factors determining this differentiation decision are not completely understood. B cells that upregulate expression of B lymphocyteinduced maturation protein 1 (BLIMP1; also known as PRDM1) and maintain expression of the orphan $\mathrm{G}$ protein-coupled receptor Epstein-Barr virus-induced gene 2 (EBI2; also known as GPR183) $)^{29,30}$ move to the bridging channels or junction zones at the boundary between the $\mathrm{T}$ cell zones and the red pulp of the spleen or move to lymph node medullary cords. At these sites they grow as plasmablasts and differentiate into extrafollicular plasma cells, which undergo a moderate degree of immunoglobulin class switching and tend to die after three days by apoptosis in the secondary lymphoid tissue where they were produced ${ }^{18}$ (TABLE 1). Under some circumstances this pathway can give rise to somatically mutated autoantibodies ${ }^{23}$. By contrast, B cells that upregulate B cell lymphoma 6 (BCL-6) expression, as a consequence of interferon-regulatory factor 8 (IRF8) expression and downregulation of EBI2, differentiate into GC B cells and undergo CXCR5-mediated migration to the follicles ${ }^{29-31}$.

In $\mathrm{T}_{\mathrm{H}}$ cells, strong $\mathrm{T}$ cell receptor binding and stable interactions involving SLAM-associated protein (SAP; also known as $\mathrm{SH} 2 \mathrm{D} 1 \mathrm{~A}$ ) with $\mathrm{B}$ cells promote $\mathrm{T}_{\mathrm{FH}}$ cell formation and entry into the $\mathrm{GC}^{32,33}$. Commitment to the $\mathrm{T}_{\mathrm{FH}}$ cell lineage also requires upregulation of BCL- 6 expression, which leads to upregulation of CXCR5 expression ${ }^{34}$. This occurs, at least in part, through BCL-6-induced repression of the microRNA cluster 17-92 (REF. 35). Although $\mathrm{T}_{\mathrm{FH}}$ cells can produce cytokines that are characteristic of other $\mathrm{T}_{\mathrm{H}}$ cell lineages, the amounts of interferon- $\gamma$ $(\mathrm{IFN} \gamma)$ and interleukin-17 (IL-17) produced by $\mathrm{T}_{\mathrm{FH}}$ cells are lower than those found in $\mathrm{T}_{\mathrm{H}} 1$ and $\mathrm{T}_{\mathrm{H}} 17$ cells, respectively ${ }^{34}$. By contrast, $\mathrm{T}_{\mathrm{FH}}$ cells produce substantial amounts of IL-21, which influences both GC B cells and $\mathrm{T}_{\mathrm{FH}}$ cells.

B cell maturation and antigen-driven selection. B cell blasts proliferate to fill the follicles and differentiate to become centroblasts, which upregulate CXCR4 expression and become located close to the $\mathrm{T}$ cell zones ${ }^{36}$ (forming the follicular dark zone) (FIG. 1). Preferential CXCR4 expression also seems to segregate centroblasts and the non-dividing progeny of centroblasts, centrocytes, in human tonsils into dark zones and light zones, respectively ${ }^{37}$. Proliferating centroblasts express activation-induced cytidine deaminase (AID; encoded by AICDA), which drives immunoglobulin class switching and the SHM machinery. Mutations are concentrated in the complementarity-determining regions (CDRs) of IgV regions and result in stochastic changes in antibody affinity and specificity. Centrocytes re-express cell surface immunoglobulin (the B cell receptor (BCR)) and can take up antigen presented by FDCs in the form of immune complexes $^{38}$. Immune complexes presented by FDCs are particularly prominent in the light zones, which are also rich in $\mathrm{T}_{\mathrm{FH}}$ cells. This spatial compartmentalization led 
Table 1 | Follicular versus extrafollicular T cell-dependent B cell responses to foreign antigens

\begin{tabular}{|c|c|c|}
\hline Parameter & Follicular & Extrafollicular \\
\hline B cell transcription factors & BCL-6 & BLIMP1 \\
\hline Localization & Secondary follicles & $\begin{array}{l}\text { Bridging channels or junction zones } \\
\text { between T cell zone and red pulp of } \\
\text { spleen; lymph node medullary cords }\end{array}$ \\
\hline $\begin{array}{l}\text { Requirement for first B cell-T cell } \\
\text { interaction in the T cell zone }\end{array}$ & Yes, CD40 signals required & Yes, CD40 signals required \\
\hline $\begin{array}{l}\text { Requirement for second } \\
\text { B cell-T cell interaction }\end{array}$ & $\begin{array}{l}\text { Yes, survival and selection signals from } \\
\mathrm{T}_{\mathrm{FH}} \text { cells are essential }\end{array}$ & $\begin{array}{l}\text { Interaction with extrafollicular T cells may } \\
\text { promote growth }\end{array}$ \\
\hline $\begin{array}{l}\text { IL-21R expression and } \\
\text { dependence }\end{array}$ & $\begin{array}{l}\text { IL-21R expressed; IL-21R signals } \\
\text { required for } \mathrm{GC} \text { formation and } \\
\text { longevity }\end{array}$ & $\begin{array}{l}\text { IL-21R signals are likely to influence the } \\
\text { magnitude of the extrafollicular responses } \\
\text { prior to plasmablast formation (IL-21R } \\
\text { downregulated in plasmablasts)* }\end{array}$ \\
\hline AID expression & Yes & Yes \\
\hline Class switching & $\begin{array}{l}\text { Yes, significant class switching occurs } \\
\text { and is initiated soon after the first } \\
\text { B cell-T cell cognate interaction in the } \\
\text { T cell zone, prior to entering the follicles }\end{array}$ & Yes, significant class switching occurs \\
\hline Somatic hypermutation & High rate & Low rate ${ }^{\ddagger}$ \\
\hline $\begin{array}{l}\text { Quality of the antibody } \\
\text { produced }\end{array}$ & High affinity & Low affinity \\
\hline $\begin{array}{l}\text { Longevity of terminally } \\
\text { differentiated B cells }\end{array}$ & $\begin{array}{l}\text { Long-lived plasma cells and memory } \\
\text { B cells }\end{array}$ & $\begin{array}{l}\text { Short-lived plasma cells (lifespan of } \\
\sim 3 \text { days) }\end{array}$ \\
\hline Homing of effector plasma cells & Bone marrow or local MALT & $\begin{array}{l}\text { Most die by apoptosis in the secondary } \\
\text { lymphoid tissues where they were produced }\end{array}$ \\
\hline
\end{tabular}

to a model in which proliferation and selection of B cells in GCs occurs in the dark zone and light zone, respectively, and cyclic re-entry of selected centrocytes into the dark zone allows further proliferation and subsequent rounds of selection to achieve the observed enrichment in replacement mutations. However, recent in vivo imaging studies challenge this model. Proliferating B cells in light zones and infrequent exchange of B cells between zones suggest that re-entry into the dark zone may not be necessary for successive rounds of BCR mutation and higher-affinity selection ${ }^{39}$.

There is strong evidence that BCR signals, FDCderived signals and $\mathrm{T}_{\mathrm{FH}}$ cell-derived signals all contribute to GC B cell survival, but the precise order and source of the cellular interactions responsible are still not clear (FIG. 2; TABLE 2). BCR signals support the survival of centrocytes; GC B cells that lack the ETS-family transcription factor SPIB, the B cell co-receptor CD45 (also known as PTPRC) ${ }^{40}$ or the GTPase TC21 (also known as RRAS2), which links BCR signalling with phosphoinositide 3-kinase (PI3K) ${ }^{41}$, undergo increased apoptosis. There is also evidence that BCR-mediated survival signals are extended when they are received together with accessory survival signals from FDCs. Robust attachments of GC B cells to FDCs have been observed in vivo by several groups (reviewed in REF. 39). Survival of tonsillar GC B cells in vitro was shown to depend on adhesion to FDCs involving interactions between lymphocyte function-associated antigen 1 (LFA1) and intercellular adhesion molecule 1 (ICAM1) and between very late antigen 4 (VLA4) and vascular cell-adhesion molecule 1 (VCAM1) that act synergistically with BCR signals ${ }^{42}$. BCR-integrin signalling has also been shown to enhance antigen uptake and presentation to T cells ${ }^{43}$. Recently, B cell expression of dedicator of cytokinesis 8 (DOCK8), a member of the Dock family of RAC-specific guanine nucleotide exchange factors, was shown to be essential for concentrating ICAM1 in the $B$ cell immunological synapse and for the persistence and affinity maturation of GC B cells, supporting the hypothesis that B cell interactions with FDCs provide crucial survival signals ${ }^{44}$.

Positive and negative selection mediated by $T_{F H}$ cells. A competition model has been proposed in which the efficiency with which centrocytes process and present antigen on MHC class II molecules to $\mathrm{T}_{\mathrm{FH}}$ cells is determined by BCR affinity for antigen ${ }^{8}$. After successful cognate interaction with centrocytes, $\mathrm{T}_{\mathrm{FH}}$ cells provide proliferation, survival and differentiation signals to centrocytes through CD40 ligand (CD40L) and cytokines, including IL-4 and IL-21 (REF. 45) (FICS 1,2). BCL-6 expression by differentiating $\mathrm{T}_{\mathrm{FH}}$ cells decreases the production of $\mathrm{T}_{\mathrm{H}} 1$ and $\mathrm{T}_{\mathrm{H}}$ 17-type cytokines favouring the production of IL-4 and IL-21 (REF. 35). Although it is clear that CD40L is essential to maintain GC reactions and for centrocyte survival $^{45}$, the individual cytokines and signals that mediate GC B cell differentiation are poorly defined. 
$\mathrm{T}_{\mathrm{FH}}$ cells can also deliver negative selection signals to centrocytes by ligating CD95 (encoded by $F A S$ ), which is highly expressed by human and mouse GC B cells. CD95 signalling limits the number of memory B cells, the accumulation of mutations in the memory B cell pool and long-term proliferation of GC $B$ cells ${ }^{46}$. Accordingly, ablation of CD95 expression by GC B cells has been shown to increase the number of GC B cells after immunization with T cell-dependent antigens $^{47}$ (FIG. 2; TABLE 2).

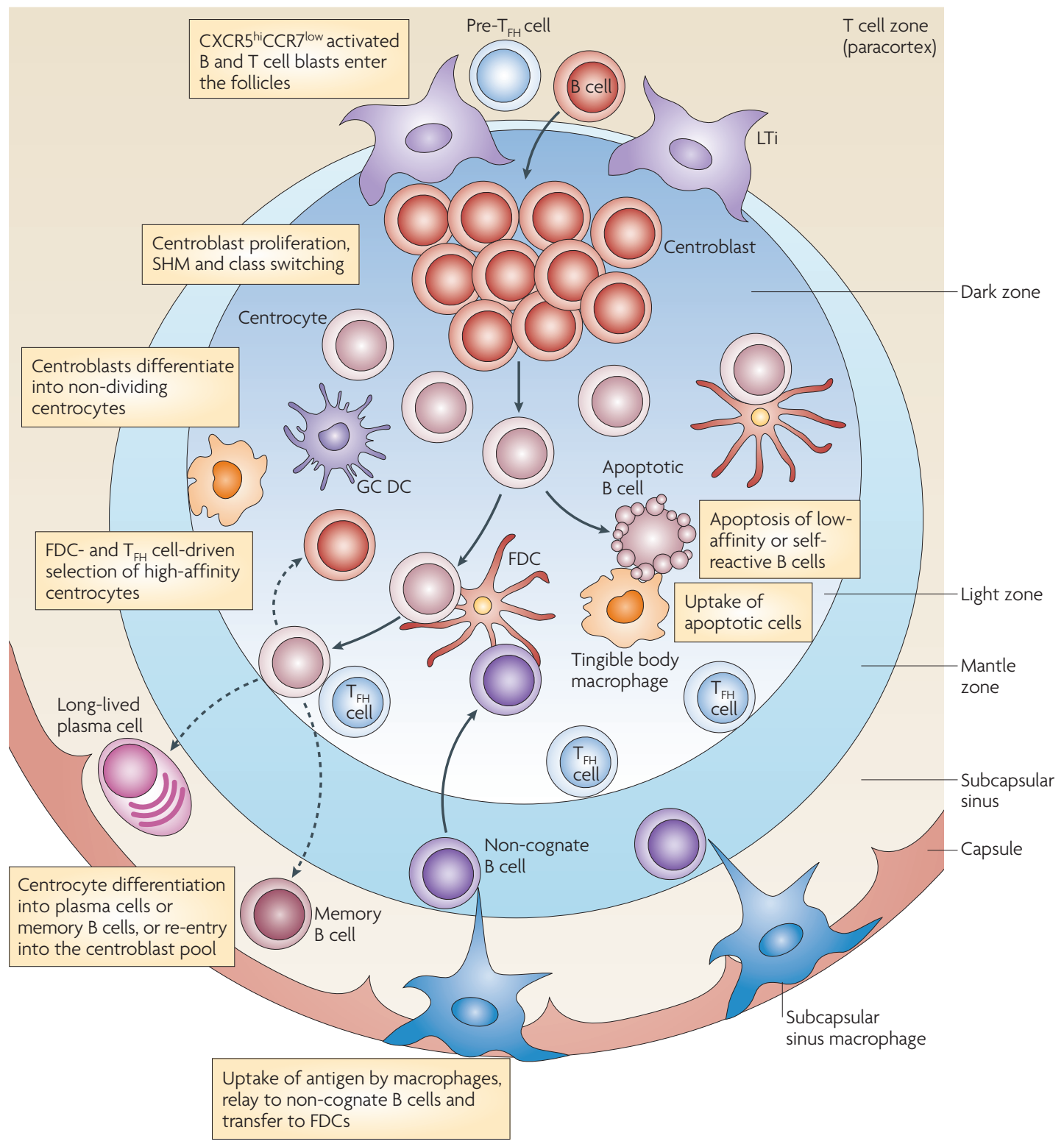

Figure 1 | Germinal centre cell types and events. A small number of activated B cells seed the follicles to grow and initiate germinal centre $(\mathrm{GC})$ reactions. T follicular helper $\left(\mathrm{T}_{\mathrm{FH}}\right)$ cells that have established stable interactions with $B$ cells at the outer T cell zone also enter follicles; they may receive survival and/or growth signals from lymphoid tissue-inducer (LTi) cells at the B cell-T cell border. Proliferation of GC B cells displaces naive circulating B cells that now form the follicular mantle zone. Two zones can be identified: the dark zone and the light zone. The dark zone is full of dividing GC B cells, known as centroblasts, although some proliferating B cells can also be found in the light zone. The light zone is rich in follicular dendritic cells (FDCs) that have antigen bound on their surface. Antigen can be picked up by subcapsular sinus macrophages from the lymph and delivered to non-cognate B cells that transfer the antigen to FDCs. FDCs bind the antigen in the form of immune complexes. Dividing centroblasts acquire somatic hypermutation (SHM) in their immunoglobulin variable-region genes; their non-dividing progeny, centrocytes, are selected after a successful interaction with FDCs, uptake of antigen through the B cell receptor and presentation of this antigen to $T_{F H}$ cells. Selection can lead to terminal differentiation into long-lived plasma cells or memory B cells or can induce centrocytes to re-enter the cell cycle and undergo further rounds of SHM. It is possible that selection signals are also received by B cells in the dark zone. Failure to receive these survival signals leads to apoptosis in situ. Apoptotic cells are cleared by tingible body macrophages. CCR7, CC-chemokine receptor 7; CXCR5, CXC-chemokine receptor 5; DC, dendritic cell. 
A germinal centre ontogeny of autoantibodies Somatic mutation of autoantibodies. Early studies showed that point mutations can transform protective antibodies into autoantibodies ${ }^{21}$. Numerous mouse and human studies have indicated that pathogenic autoantibodies, typically class-switched IgG antibodies, show evidence of SHM and antigen-driven selection ${ }^{5,48-50}$. Although in many cases the actual relationship between the two processes can only be inferred from the ratio of observed to expected amino acid replacements and

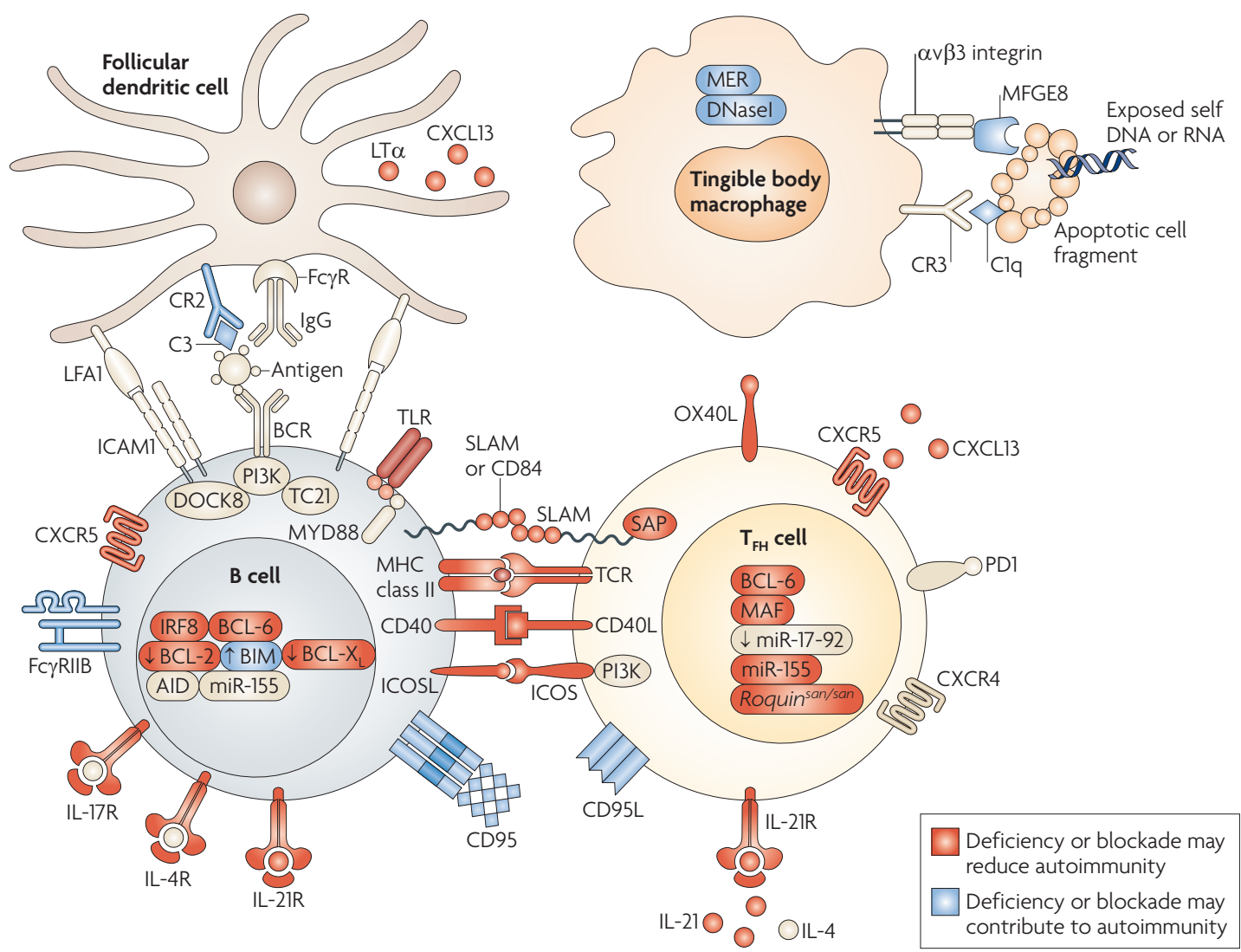

Figure 2 | Molecular basis of germinal centre events and potential therapeutic intervention. A summary of molecular signals that govern cellular interactions in germinal centres (GCs) that when blocked might reduce (red) or enhance (blue) autoimmunity of follicular origin. Survival of GC B cells that have undergone somatic hypermutation mediated by activation-induced cytidine deaminase (AID) depends on establishing a B cell immunological synapse that requires dedicator of cytokinesis 8 (DOCK8) and involves a ring of the integrin intercellular adhesion molecule 1 (ICAM1) surrounding the $B$ cell receptor (BCR) on the GC B cell, and lymphocyte function-associated antigen 1 (LFA1) and bound antigen on follicular dendritic cells (FDCs). FDC development requires lymphotoxin- $\alpha$ (LTa) and CXC-chemokine ligand 13 (CXCL13), and FDCs display antigen in the form of immune complexes (bound by Fc receptors for lgG (Fc $\gamma$ Rs) and complement receptors (CRs)) that deliver $\mathrm{BCR}$-mediated survival signals through activation of phosphoinositide 3-kinase (PI3K) and TC21. Antigen processed by GC B cells is presented on MHC class II molecules to T follicular helper $\left(\mathrm{T}_{\mathrm{FH}}\right)$ cells, which influence GC B cell growth and survival through the secretion of interleukin-4 (IL-4) and IL-21 and the transient upregulation of CD40 ligand (CD40L). In the absence of BCR-, integrin- and $\mathrm{T}_{\mathrm{FH}}$ cell-mediated signals that induce expression of $\mathrm{B}$ cell lymphoma 2 (BCL-2) and BCL-X in GC B cells, a pro-apoptotic programme determined by high levels of BCL-2-interacting mediator of cell death (BIM), and ligation of CD95 (encoded by FAS) leads to $B$ cell apoptosis. Expression of BCL-6 by both GC B cells and $T_{F H}$ cells is essential for successful $G C$ reactions. Effective $T_{F H}$ cell help also requires signalling through SLAM-associated protein (SAP; also known as SH2D1A) downstream of signalling lymphocytic activation molecule (SLAM) family members and T cell receptor (TCR) signals, upregulation of CXC-chemokine receptor 5 (CXCR5) expression normally following BCL-6-mediated repression of the microRNA miR-17-92 and expression of miR-155. Signals important for $\mathrm{T}_{\mathrm{FH}}$ cell generation and survival include those transmitted through inducible T cell co-stimulator (ICOS) to PI3K, IL-21 receptor (IL-21R) and OX40L. Mutations in Roquin (also known as Rc3h1) and overexpression of ICOS, OX40 L and Toll-like receptor 7 (TLR7) contribute to $T_{F H}$ cell accumulation and autoimmunity. Autoimmunity also arises when $T_{F H}$ cells produce excessive amounts of IL-17, which retains B cells in GCs, or when GC B cells express low levels of the inhibitory receptor Fc $\gamma$ RIIB. Apoptotic cells pose a risk for autoimmunity owing to exposed systemic lupus erythematosus-associated autoantigens on their surface, which can also potentially deliver activating signals through TLRs to myeloid differentiation primary-response protein 88 (MYD88) on GC B cells. This risk is mitigated through clearance of apoptotic cells by tingible body macrophages, which requires expression of DNasel and MER by macrophages and bridging molecules between macrophages and apoptotic cells, such as milk fat globule EGF factor 8 protein (MFGE8, also known as lactadherin) and complement component 1q (C1q). IRF8, interferon-regulatory factor 1 ; L, ligand; MAF, macrophage-activating factor; PD1, programmed cell death 1; R, receptor. 
Table 2 | Factors that control germinal centre tolerance

\begin{tabular}{|c|c|c|}
\hline GC component & Quality & Quantity \\
\hline B cells & $\begin{array}{l}\text { - Positive selection: BCR signals (TC21*, PI3K, CD45 and SPIB accessory } \\
\text { molecules), B cell-FDC synapse (DOCK8 and ICAM1) and } T_{F H} \text { cell } \\
\text { derived signals (CD40L and IL-21) } \\
\text { - Negative selection: } T_{F H} \text { cell signals (CD95L) } \\
\text { - Recruitment signals: T cell help, low CCR7 and low EBI2 }\end{array}$ & $\begin{array}{l}\text { - Development and proliferation: IRF8 and PU.1, } \\
\text { BCL-6, IL-21R, TLRs and MYD88 } \\
\text { Pro-apoptotic programme: high AID, high CD95, high } \\
\text { BIM, low BCL-2, low BCL-X } \\
\text { - Inhibitory signals: Fc } \gamma \text { RIIB }\end{array}$ \\
\hline $\mathrm{T}_{\mathrm{FH}}$ cells & $\begin{array}{l}\text { - Cytokine production: low IL-17, IFN } \gamma \text { and high IL-21 } \\
\text { - miR-155 } \\
\text { - Help to B cells: SAP, CD40L and IL-21 }\end{array}$ & $\begin{array}{l}\text { Development: high BCL-6, low BLIMP, MAF, ICOS, } \\
\text { IL-21R, OX40L and Roquin }{ }^{\text {san/SAN }} \\
\text { - Recruitment to GC: CXCR5, low miR-17-92, and SAP } \\
\text { - Clonal expansion: IL-21 } \\
\text { - Survival: ICOS }\end{array}$ \\
\hline FDCs & - Antigen presentation: CR2, FcR and LFA1 & $\begin{array}{l}\text { - FDC numbers and de novo development: LTa, } \\
\text { CXCL13 }\end{array}$ \\
\hline Antigen & $\begin{array}{l}\text { - Immunogenicity and availability: post-translational modification, } \\
\text { structural features, developmental isoforms and abundant TLR } \\
\text { ligands (self DNA and RNA) exposed on apoptotic cells }\end{array}$ & $\begin{array}{l}\text { - Genetic differences in expression: HLA and antigen } \\
\text { gene variants } \\
\text { - Disposal of apoptotic cells by macrophages: MFGE8, } \\
\text { DNasel, MER and C1q }\end{array}$ \\
\hline
\end{tabular}

AID, activation-induced cytidine deaminase; BCL, B cell lymphoma; BCR, B cell receptor; BIM, BCL-2-interacting mediator of cell death; C1q, complement component 1q; CCR, CC-chemokine receptor; CR2, complement receptor 2; CXCL, CXC-chemokine ligand; CXCR, CXC-chemokine receptor; DOCK8, dedicator of cytokinesis 8; EBI2, Epstein-Barr virus-induced gene 2 (also known as GPR183); FcR, Fc receptor; FDC, follicular dendritic cell; GC, germinal centre; ICAM1, intercellular adhesion molecule 1; ICOS, inducible T cell co-stimulator; IL, interleukin; IL-21R, interleukin-21 receptor; IFN $\gamma$, interferon- $\gamma$; IRF8, interferonregulatory factor 8; L, ligand; LFA1, lymphocyte function-associated antigen 1; LTa, lymphotoxin- $\alpha$; MAF, macrophage-activating factor; MFGE8, milk fat globule-EGF factor 8 (also known as lactadherin); MYD88, myeloid differentiation primary-response protein 88; PI3K, phosphoinositide 3-kinase; SAP, SLAM-associated protein (also known as SH2D1A); $\mathrm{T}_{\mathrm{FH}}$, T follicular helper; TLR, Toll-like receptor. *also known as RRAS2. ${ }^{\ddagger}$ also known as TNFSF4.

\section{Rheumatoid factor}

An autoantibody against the Fc portion of IgC present at high levels in $80 \%$ of patients with rheumatoid arthritis and almost $100 \%$ of patients with Sjögren's syndrome.

Rheumatoid factor and IgG join to form immune complexes, which contribute to disease.

MRL/Ipr mice

A mouse strain that

spontaneously develops glomerulonephritis and other symptoms of SLE. The Ipr mutation causes a defect in CD95, preventing the apoptosis of activated lymphocytes; the MRL strain contributes disease-associated mutations that have yet to be identified.

Systemic lupus erythematosus

(SLE). A chronic autoimmune disease in which

autoantibodies against double-stranded DNA

contribute to inflammation and tissue damage, usually

affecting the heart, joints, skin, lungs, blood vessels, liver,

kidneys and nervous system. silent mutations found in antigen-binding hypervariable regions ${ }^{51}$, direct measurements of the effect of SHM on the selection of autoreactive antibodies have also been provided by numerous studies. Elegant genealogical analysis of rheumatoid factor and DNA-specific antibodies in MRL//pr mice ${ }^{48}$ showed that autoantibodies in this autoimmune strain were oligoclonal in origin and displayed patterns of antigen-selected SHM, thereby providing initial evidence against random polyclonal B cell expansions as the source of autoantibody production. Moreover, studies of clonal variants have established the role for SHM in the 'spreading' of mouse autoimmune responses across related autoantigens, including nucleosomes, DNA and cardiolipin ${ }^{52}$. Reverse mutation in vitro has been used to show how SHM results in the stepwise acquisition of disease-associated autoreactivity of human DNA-specific autoantibodies ${ }^{53}$.

Dysregulated GCs in animal models of autoimmune disease. Autoantibodies with the hallmarks of a GC origin are also found in numerous animal models for systemic lupus erythematosus (SLE). Furthermore, strains of mice that typically develop autoimmune SLE-like disease or insulitis (PN, NZB, NZB/W F1, $\mathrm{BXSB}, \mathrm{MRL}, \mathrm{MRL} / \mathrm{lpr}, \mathrm{C} 57 \mathrm{BL} / 6 / l p r$, sanroque and non-obese diabetic (NOD) mice) exhibit spontaneous GC formation in the spleen by 1-2 months of age in the absence of either purposeful immunization or infection ${ }^{54}$ (TABLE 3). Spontaneous GC formation correlates with the onset of autoantibody production. Spontaneously formed GCs are also found in $\mathrm{K} / \mathrm{BxN}$ mice, which develop autoimmune arthritis. Although the pathology is organ-specific, it is mediated by highaffinity autoantibodies to a ubiquitous self antigen, and spontaneous GCs form in lymph nodes draining the affected joints and in the spleen ${ }^{55}$.
Ectopic GCs in autoimmune disease. In other organspecific autoimmune diseases, in which expression of the targeted self antigen is often tissue restricted, organized ectopic lymphoid structures with GCs form at the site of tissue pathology ${ }^{56}$. Ectopic GCs have been noted in exocrine glands, liver, synovium and thymus but, curiously, not in neuro-ectoderm-derived tissues. Indeed, ectopic GCs are found in $25-50 \%$ of patients with rheumatoid arthritis. Ectopic GCs contain most of the components of conventional GCs, although they lack afferent lymphatics and possibly also the conduits and 'corridors' and are not part of an encapsulated lymphoid structure.

It is possible that ectopic GCs might generate and amplify autoreactivity or, alternatively, censor autoreactivity that arises during B cell proliferation and SHM. The possibility that highly organized ectopic GCs might reduce the chance of autoantibody formation during inflammatory responses is consistent with recent evidence from studies of the synovium from patients with rheumatoid arthritis ${ }^{57}$. It would also explain the correlation between responsiveness to therapy with rituximab (rituxan, Genentech, Inc. and Biogen Idec; monoclonal CD20-specific antibody) and the extent of GC organization in tonsils ${ }^{58}$. Significantly, GCs in patients who responded to rituximab therapy were better at censoring autoreactive 9G4 B cells ${ }^{59}$. By contrast, a defect in censoring autoreactive $9 \mathrm{G} 4 \mathrm{~B}$ cells is characteristic of patients with untreated SLE.

However, there is evidence that ectopic GCs contribute to autoimmune pathology as they form in sites adjacent to sources of autoantigen, are a source of somatically mutated high-affinity autoantibodies and in some cases correlate with disease activity ${ }^{60-63}$. Recent studies suggest that they can arise de novo from naive $\mathrm{B}$ cells ${ }^{64}$. Expression of AICDA and activation of class switching and SHM have been shown to occur in the 
Table 3 | Spontaneous mouse models* of autoimmunity to ubiquitous self antigens

\begin{tabular}{|c|c|c|c|c|}
\hline Mouse strain & Manifestations & $\begin{array}{l}\text { Immunoglobulin } \\
\text { titre }\end{array}$ & Autoantibodies & $\begin{array}{l}\text { Germinal } \\
\text { centres }\end{array}$ \\
\hline $\mathrm{BXSB} / \mathrm{Yaa}$ & $\begin{array}{l}\text { Glomerulonephritis, UV-accelerated } \\
\text { skin disease and splenomegaly }\end{array}$ & Increased & Antinuclear and dsDNA-specific & Increased \\
\hline NZW/BXSB & $\begin{array}{l}\text { APS, ITP, Sjögren's syndrome and } \\
\text { hepatitis }\end{array}$ & Increased & dsDNA-, cardiolipin- and GPIIb-IIla-specific & Increased \\
\hline MRL/lpr & $\begin{array}{l}\text { Glomerulonephritis, skin changes and } \\
\text { splenomegaly }\end{array}$ & Increased & Antinuclear and dsDNA-specific & Increased \\
\hline Sanroque & $\begin{array}{l}\text { Glomerulonephritis, splenomegaly and } \\
\text { thrombocytopaenia }\end{array}$ & Increased & Antinuclear and dsDNA-specific & Increased \\
\hline $\mathrm{K} / \mathrm{BxN}$ & Peripheral arthritis & Increased & Glucose-6-phosphate isomerase-specific & Increased \\
\hline
\end{tabular}

NZB mice

An inbred autoimmunity-prone mouse strain that spontaneously develops an SLE-like disease,

characterized by autoimmune (Coombs test-positive)

haemolytic anaemia and glomerulonephritis. F1 hybrids with NZW (derived from the same outbred stock as NZB) develop a disease that closely resembles human SLE, characterized by high titres of autoantibodies and glomerulonephritis.

$\mathrm{K} / \mathrm{BxN}$ mice

Mice that express both the KRN $T$ cell receptor transgene and the NOD-derived MHC class II molecule $\mathrm{I}^{-\mathrm{A}^{\mathrm{g}} \mathrm{T}}$ and develop severe inflammatory arthritis as a result of the specificity of the transgenic TCR for a peptide derived from the ubiquitously expressed self protein glucose-6-phosphate isomerase in the context of $\mathrm{I}-\mathrm{A}^{\mathrm{g} 7}$.

Ectopic lymphoid structures (Also known as tertiary lymphoid organs). Organized lymphocytic aggregates that form at sites of chronic inflammation. Typically, B celland $\mathrm{T}$ cell-rich zones are segregated, and dendritic cells (DCs), germinal centres with follicular DC (FDC) networks and specialized endothelia are present. synovial GCs obtained from patients with rheumatoid arthritis. Furthermore, when these synovial GCs were transplanted into severe combined immunodeficient mice, antibodies specific for cyclic citrullinated peptide were detected in the serum of the recipient animals. The findings are interesting given that cyclic citrullinated peptide-specific antibodies are strongly associated with rheumatoid arthritis and highly predictive for the development of erosive disease ${ }^{65}$.

\section{Extrafollicular origin of autoantibodies}

Although the focus of this Review is the mechanisms that result in autoantibody production by GCs, in several mouse models autoantibodies originate from extrafollicular B cell responses. In MRL/lpr mice, which have a homozygous loss of function mutation in Fas (which encodes CD95), rheumatoid factor production and DNA-specific antibody formation occur in extrafollicular sites $^{22-25}$. In these mice, extrafollicular plasma cells have been found to be somatically mutated ${ }^{23}$. Furthermore, AM14 rheumatoid factor-positive B cells on an MRL/lpr background can be activated by self antigen (chromatin-specific IgG2b) independently of T cell help, although the absence of $\mathrm{T}$ cells resulted in fewer autoreactive plasma cells and less somatic mutation ${ }^{66}$. The production of autoantibodies in MRL/lpr mice depends on myeloid differentiation primary-response protein 88 (MYD88) signals downstream of Toll-like receptor 9 (TLR9) (for DNA-specific antibodies) and/or TLR7 (for RNA-specific antibodies) ${ }^{67}$. Indeed, there is evidence that uptake of antigen conjugated with a TLR9 ligand through the BCR induces a predominantly extrafollicular plasma cell response ${ }^{68}$.

B cell-activating factor (BAFF; also known as TNFSF13B)-transgenic mice also develop an SLE-like disease associated with DNA-specific antibodies in the absence of $\mathrm{T}$ cells ${ }^{26}$, and the DNA-specific responses observed in a spontaneous SLE model $(\mathrm{C} 57 \mathrm{BL} / 6 \times 56 \mathrm{R}$ mice) occur independently of T cells and TLR signals ${ }^{27}$. Importantly, recent findings suggest that in several mouse models of autoimmunity, follicular and extrafollicular autoantibody responses may occur at the same time. For example, in BXSB/Yaa mice, both $\mathrm{T}_{\mathrm{FH}}$ cells and extrafollicular $\mathrm{T}$ cells produce high amounts of IL-21 and therefore both can presumably support terminal B cell differentiation ${ }^{69}$.

\section{GC components and autoimmunity}

Autoantibodies can arise from defects in binary tolerance checkpoints in GCs - of which the outcome is either B cell death or survival. Non-mutually exclusive mechanisms involve aberrant persistence of GCs owing to abnormal cellular components, abnormal signals or aberrant availability of self antigen (TABLE 2).

B cell-intrinsic signals in GCs. Follicular B cell responses depend on efficient delivery of cognate $\mathrm{T}$ cell help in the outer $\mathrm{T}$ cell zone. As central $\mathrm{T}$ cell tolerance is far more efficient than central B cell tolerance ${ }^{70}$, many autoreactive $B$ cells fail to progress beyond this checkpoint ${ }^{71,72}$. Alternatively, autoreactive B cells may become anergic. Anergic B cells cannot compete for a limited supply of $\mathrm{BAFF}$, which is required for $\mathrm{B}$ cell survival ${ }^{73}$, are refractory to activation and $\mathrm{T}$ cell help ${ }^{72}$, and fail to be recruited to the intrafollicular response. In rare cases, $\mathrm{T}$ cells may help autoreactive $\mathrm{B}$ cells owing to cross reactivity between bacterial or viral antigens and self antigens leading to autoantibody production ${ }^{74}$. The rarity of these occurrences suggests that intrinsic tolerance mechanisms prevent the differentiation of autoreactive B cells in most cases.

Microorganisms express ligands for TLRs on B cells, which can partially substitute for T cell help ${ }^{75}$. How TLR signalling thresholds are regulated to prevent activation of autoreactive B cells is not clear but there is evidence that both TLR9 and TLR7 pathways (which sense 


\section{G4 B cells}

$B$ cells that make autoreactive antibodies that target the $\mathrm{I} / \mathrm{i}$ blood group antigen and related determinants present in CD45 and other self glycoproteins. High titres of these antibodies are found in patients with active SLE and contribute a significant fraction of native double-stranded DNA-specific antibodies in these patients.

\section{BXSB/Yaa mice}

An autoimmunity-prone

strain of mouse (BXSB) with the $Y$ chromosome-linked

autoimmune accelerator (Yaa) mutation, which is a

duplication and translocation

of a segment of the

$\mathrm{X}$ chromosome that contains

several genes, including Toll-like receptor 7 (TIr7), to the

$Y$ chromosome. Male BXSB mice develop a severe form of

SLE with a much higher incidence than their female counterparts.

\section{Anergy}

A state of non-responsiveness to antigen. Anergic $B$ or $T$ cells cannot respond to their cognate antigens under optima conditions of stimulation.

\section{Bz-423}

A pro-apoptotic

1,4-benzodiazepine that induces cell cycle arrest and apoptosis by promoting the formation of superoxide in the mitochondrial respiratory chain, which leads to the activation of pro-apoptotic proteins. It has been used in mouse models of SLE in which it seems to selectively target autoreactive lymphocytes.

Erythroblastic islands Specialized bone marrow niches comprising erythroblasts surrounding a central macrophage where erythroid precursors proliferate differentiate and enucleate.

Tingible body macrophages (TBMs). A type of macrophage that is specifically located in GCS. TBMs are found in close proximity to follicular dendritic cells, and engulf lymphocytes that undergo apoptosis in the GCs. TBMs can also have an inhibitory effect on the

B cell-mediated stimulation of $T$ cell responses when added to ex vivo co-cultures.
CpG-containing DNA and single-stranded RNA, respectively) can drive autoantibody formation ${ }^{76-78}$. As mentioned above, TLRs seem to have a role in autoantibody responses of extrafollicular origin in MRL/lpr mice. TLR signalling also influences GC B cells, although it is not known whether this has any consequences for autoimmunity. In the absence of B cell-expressed MYD88, GCs are significantly reduced in both number and size ${ }^{79}$. Also, GC B cells are more easily activated in the presence of LPS and CD40 ligation than follicular or marginal zone $\mathrm{B}$ cells $\mathrm{s}^{80}$. This, together with the large amounts of exposed self DNA and RNA on the surface of GC $\mathrm{B}$ cells undergoing apoptosis, raises the possibility that TLR signalling to GC B cells may override the need for $\mathrm{T}_{\mathrm{FH}}$ cell-mediated selection and allow the emergence of autoreactive clones.

GC B cells exhibit a pro-apoptotic programme of gene expression - downregulation of $\underline{B C L-2}$ and $\underline{B C L-} X_{L}$ (also known as BCL2L1) and upregulation of BCL-2interacting mediator of cell death (BIM; also known as BCL2L11) - that limits the lifespan of centrocytes that fail to receive antigen-, FDC- and $\mathrm{T}_{\mathrm{FH}}$ cell-derived survival signals ${ }^{81}$. Overexpression of $B c l 2$ decreases the amount of GC B cell apoptosis, leads to the expansion of low-affinity memory $\mathrm{B}$ cell populations $\mathrm{s}^{82}$ and interferes with the apoptosis of autoreactive $B$ cells $s^{83}$. BCL-X overexpression has similar effects on affinity maturation and negative selection of autoreactive B cells ${ }^{84}$. BIM also regulates the apoptosis of GC B cells bearing lowaffinity BCRs ${ }^{85}$. This propensity of GC B cells to die by apoptosis has been tested for therapeutic potential using Bz-423, a 1,4-benzodiazepine that induces the activation of the pro-apoptotic proteins BCL-2 antagonist/killer (BAK) and BCL-2-associated $\mathrm{X}$ protein (BAX) and is specific for GC B cells in vivo. After 12 weeks, Bz-423 reduced the number and size of GCs in NZB/W F1 mice, increased B cell apoptosis in remaining GCs and reduced glomerulonephritis and early mortality ${ }^{86}$.

Low-affinity Fc receptor for IgG (Fc $\gamma$ RIIB) is the only $\mathrm{Fc} \gamma \mathrm{R}$ that is expressed by $\mathrm{B}$ cells and has been implicated in GC regulation and enhanced plasma cell formation ${ }^{87}$. Fc $\gamma$ RIIB is expressed at lower levels by GC B cells from autoimmunity-prone NZB and NZB/W F1 mice ${ }^{88}$, and patients with SLE show defects in upregulation of Fc $\gamma$ RIIB expression by memory B cells and plasma cells ${ }^{89,90}$. Deficiency of Fc $\gamma$ RIIB increases susceptibility to collageninduced arthritis ${ }^{91}$ and strain-dependent susceptibility to SLE-like glomerulonephritis ${ }^{22}$. Several Fc $\gamma$ Rs, including Fc $\gamma$ RIIB, are encoded within an SLE susceptibility locus in humans and mice on chromosome 1 (REF. 93). The SLElike phenotype in autoimmunity-prone mouse strains was corrected by partial restoration of $\mathrm{Fc} \gamma \mathrm{RIIB}$ expression by haematopoietic cells ${ }^{94}$.

FDCs. The requirement for survival signals delivered by FDCs at the time of BCR binding of specific antigen presented bound to IgG by FDCs - has been proposed to provide an explanation for the rapid death of GC B cells that bind soluble (usually self) antigen ${ }^{95-97}$. Conversely, interactions between B cells and FDCs may be required for the generation of pathological autoantibodies in mice and humans ${ }^{56,98}$. In the $\mathrm{K} / \mathrm{BxN}$ mouse model of arthritis, in which the development of arthritis depends on the production of pathogenic autoantibodies (and is associated with formation of numerous GCs), depletion of FDCs resulted in amelioration of arthritis and a reduction in pathogenic antibody titres ${ }^{55}$. De novo formation of FDCs to sustain ectopic GCs occurs from tissue-resident fibroblasts or their precursors ${ }^{99}$. Availability of these precursors could be a limiting factor in lymphoid neogenesis and could explain the absence of ectopic lymphoid structures in certain tissues. A further link between FDCs and autoimmunity has also been suggested by a study showing that polymorphisms in the gene encoding complement receptor 2 ( $\underline{C R} 2$; also known as CD21) associated with SLE and modulated alternative splicing of an exon preferentially expressed by $\mathrm{FDCs}^{100}$.

Antigen: quantity and quality. Most foreign and self antigens enter GCs from elsewhere, but some are a byproduct of GCs themselves. GCs, similar to erythroblastic islands in the bone marrow, are sites of marked apoptosis, and specialized macrophages dedicated to phagocytosis of apoptotic debris exist in both locations. In GCs, these are called tingible body macrophages ${ }^{101}$. Important SLEassociated autoantigens are abundant on apoptotic bodies ${ }^{102}$, and effective disposal of these apoptotic bodies seems to be crucial to prevent autoimmunity. For example, milk fat globule-EGF factor 8 protein (MFGE8; also known as lactadherin) is expressed by tingible body macrophages and binds phosphatidylserine exposed on the surface of apoptotic cells and $\alpha \mathrm{V} \beta 3$ integrin or $\alpha \mathrm{V} \beta 5$ integrin on the surface of macrophages and immature dendritic cells (DCs). Mice deficient in MFGE8 develop ANAs and glomerulonephritis ${ }^{103}$. Other defects in disposal of apoptotic cells, including deficiency of DNaseI, the receptor tyrosine kinase MER, transglutaminase 2, complement component $\mathrm{Clq}$ (the most penetrant single gene defect associated with SLE in humans) and peroxisome proliferator-activated receptor- $\delta(\operatorname{PPAR} \delta)^{160}$ all compromise the clearance of apoptotic cells and result in ANA formation ${ }^{104-107}$ (FIG. 2; TABLE 2).

The explanation for the antigen specificity of autoantibodies in other autoimmune diseases remains uncertain, but there are several clues that the quantity and quality of the autoantigen is important. Bona fide autoantibody-mediated diseases are characterized by highaffinity autoantibodies (Supplementary information S1 (table)) specific for a narrow range of epitopes, usually expressed by only one of the many available tissue-restricted antigens in the target organ, suggesting efficient selection of specific GC B cells that recognize these self antigens ${ }^{108}$. In the small subset of these diseases that have been subject to genome-wide association analysis, polymorphisms in genes encoding autoantigens have often been identified as susceptibility loci ${ }^{109-111}$. Although further work is required, several possible explanations could account for the unique availability, immunogenicity and breakdown in tolerance to these self antigens. Some antigens seem to be particularly subject to post-translational modification, either during apoptosis or for normal function. 
Such modifications could generate new antigens not encountered during central tolerance ${ }^{112}$. Antigenicity might also vary according to saturation of enzymatic pathways ${ }^{113}$. Indeed, in some situations, both enzyme and substrate have been identified as key autoantigens (for example, thyroglobulin and thyroid peroxidase, and gliadin and transglutaminase 2). Other modifications include switching of developmental isoforms (for example, the acetylcholine receptor (AChR)), inherent structural features that render self antigens immunogenic (for example, thyroid stimulating hormone receptor) ${ }^{114,115}$ and genetically specified differences in expression (for example, AChR $)^{116}$. Apart from SLE, in which the autoantigen arises in situ in GCs, antigen abundance would be predicted to be a key variable in determining where ectopic GCs form. As ectopic GCs lack afferent lymphatics, formation is presumably driven by antigen diffusing from the surrounding inflammatory milieu.

Control of $T_{F H}$ cell numbers and quality. Although the prevailing theory of autoreactivity from GCs has focused on the failure to eliminate autoreactive B cells (through negative selection), there is accumulating evidence that aberrant positive selection of autoreactive $B$ cells by dysregulated $\mathrm{T}_{\mathrm{FH}}$ cells also contributes to autoimmunity.

$\mathrm{T}$ cell migration into GCs depends on upregulation of CXCR5 expression, which requires co-stimulation. In the absence of TLR signals, as occurs after encounter with self antigen or after tolerizing immunization protocols, antigen-specific $\mathrm{T}$ cells are excluded from the follicles ${ }^{117}$. Mathematical models have predicted that limiting the number of $\mathrm{T}_{\mathrm{FH}}$ cells per GC is likely to be crucial for ensuring that there is competition for selection and survival of high-affinity $\mathrm{B}$ cell mutants ${ }^{118}$. Many mouse strains prone to SLE-like disease, including those overexpressing OX40L or TLR7 or those bearing a mutation in the Roquin (also known as Rc3h1) gene (sanroque mice), have increased numbers of $\mathrm{T}_{\mathrm{FH}}$ cells and DNA-specific antibody development ${ }^{119-122}$. Several lines of evidence suggest that this is a causal association. SLE-like disease in sanroque mice is caused by Roquin $n^{\text {san/san }}$-induced accumulation of $\mathrm{T}_{\mathrm{FH}}$ cells that sustain spontaneously formed GCs ${ }^{121,123}$; transfer of $\mathrm{T}_{\mathrm{FH}}$ cells from sanroque mice into wild-type mice leads to spontaneous GC formation ${ }^{123}$. Deficiency of Sh2dla (which encodes SAP) does not abrogate extrafollicular antibody responses but selectively precludes formation of the subset of $\mathrm{T}_{\mathrm{FH}}$ cells that localizes to GCs ${ }^{123}$, abrogating GC responses in mice and humans ${ }^{33}$. SAP deficiency also abrogates the SLE-like phenotype of sanroque mice. In addition, glomerulonephritis and pathogenic autoantibody development in sanroque mice can also be reduced by haploinsufficiency of Bcl6 (REF. 23 ), which decreases GC numbers as well as $\mathrm{T}_{\mathrm{FH}}$ cell numbers ${ }^{35}$.

Engagement of CD95 by CD95 ligand (CD95L; encoded by FASLG) on $\mathrm{T}_{\mathrm{FH}}$ cells has been suggested to induce negative selection of autoreactive GC B cells. CD95-deficient MRL/lpr mice and CD95L-deficient MRL/gld mice develop an SLE-like autoimmune disease ${ }^{124,125}$. B cell CD95 expression is key to preventing autoimmune disease $\mathrm{e}^{47,126}$. Further evidence of CD95dependent elimination of GC B cells comes from the observed death of dual-reactive (to both self and foreign antigen) B cells in the presence of CD95-deficient T cells expressing elevated levels of CD95 $\mathrm{L}^{127}$. An increase in the proportion of spontaneously arising GC B cells in the mesenteric lymph nodes of mice with a conditional deletion of CD95 in GC B cells suggests that CD95 signalling induces apoptosis of autoreactive GC B cells ${ }^{47}$. However, CD95 deficiency in these mice affects the extrafollicular plasma cell compartment as well, leaving uncertainty about whether GC-specific CD95 deletion explains the fatal lymphoproliferation and autoimmunity found in mice with CD95-deficient B cells.

$\mathrm{T}_{\mathrm{FH}}$ cell 'quality' also matters. Bcl6 expression by human $\mathrm{T}_{\mathrm{FH}}$ cells has been shown to repress the transcription factors T-bet (also known as TBX21) and retinoic acid receptor-related orphan receptor- $\gamma \mathrm{t}(\mathrm{ROR} \gamma \mathrm{t})$ and reduce IFN $\gamma$ and IL-17 production ${ }^{34}$. This may help to limit production of the antibody isotypes that are associated with some autoimmune responses (such as IgG2a in mice) and curtail GC B cell survival. Indeed, aberrant expression of IL-17 in GCs has been proposed to explain autoimmunity in BXD2 mice, which develop spontaneous GCs and pathogenic autoantibodies that cause erosive arthritis ${ }^{128}$ (TABLE 3). The autoimmune phenotype has been attributed to IL-17 receptor (IL-17R)-dependent expression of regulator of G-protein signalling 13 (RGS13) and/or RGS16, which determined the length of time that $\mathrm{B}$ cells were retained in the GCs. This remains to be proved, although it is a mechanism that is consistent with observations in C57BL/6/lpr mice, which show enhanced SHM, longer retention of B cells in the GCs and autoimmunity ${ }^{46,129}$. The precise phenotype of the IL-17-secreting T cells in this model remains uncertain, but they seem to be located in GCs. Other data suggest that cells with a $\mathrm{T}_{\mathrm{FH}}$ cell phenotype $\left(\mathrm{CXCR}^{+} \mathrm{ICOS}^{+}\right.$) can produce IL-17 in NZB/W F1 mice and that these cells are instrumental in autoantibody formation ${ }^{130}$.

Excessive production of IL-21, which promotes class switch recombination, plasma cell formation and GC longevity, also contributes to SLE-like disease in $\mathrm{BXSB} / \mathrm{Ya} a$ and MRL/lpr mice. Il21 transcripts and serum levels of IL-21 protein are elevated in BXSB/Yaa but not BXSB mice. The Yaa locus exacerbates disease when crossed onto several SLE-prone strains including BXSB, Fc $\gamma$ RIIB-deficient and Sle1 mice. This Yaa effect is explained by overexpression of TLR7 (REF. 131), which has been translocated together with a cluster of X chromosome-linked genes onto the Y chromosome $e^{122,132}$. Yaa acts both B cell-intrinsically and extrinsically to promote autoantibody formation ${ }^{132}$. C57BL/6.Sle1/Yaa CD $4^{+}$ $\mathrm{T}$ cells have a gene expression signature of $\mathrm{T}_{\mathrm{FH}}$ cells, with high levels of inducible T cell co-stimulator (ICOS), programmed cell death 1 (PD1) and CXCR5 expressed on their surface ${ }^{122}$. However, IL-21 in these mice is produced by all ICOS ${ }^{+} \mathrm{T}$ cells, including both bona fide $\mathrm{T}_{\mathrm{FH}}$ cells and extrafollicular cells, suggesting a mixed follicular and extrafollicular origin of the autoantibody response ${ }^{69}$. Also, in MRL/lpr mice that are prone to an SLE-like disease there is evidence that extrafollicular T cells can produce IL-21 (REF. 133). In mice, extrafollicular plasmablasts have been shown to downregulate IL-21R expression during 
responses to foreign protein antigens ${ }^{134}$. It is possible that excessive IL-21 production in these autoimmune mouse models acts to boost B cell responses at a stage before plasmablast differentiation, possibly during initial B cell-T cell interactions in the T cell zone.

Cell-cell interactions have also been implicated in regulating $\mathrm{T}_{\mathrm{FH}}$ cell numbers and function. A regulatory subset of T cells $\left(\mathrm{CD} 4^{+} \mathrm{CD} 25^{+}\right)$that expresses the latencyassociated peptide (LAP) of transforming growth factor- $\beta$ has been shown to downregulate IL-17 production by $\mathrm{T}_{\mathrm{FH}}$ cells $\mathrm{s}^{130}$. Similar findings have been reported in humans: follicular $\mathrm{CXCR} 5^{+} \mathrm{CD} 4^{+} \mathrm{CD} 25^{+} \mathrm{CD} 69^{-}$regulatory $\mathrm{T}$ cells have been described that suppress the helper effects of $\mathrm{T}_{\mathrm{FH}}$ cells ${ }^{135}$. Finally, cytotoxic $\mathrm{T}$ lymphocyte antigen 4 (CTLA4) expression has also been shown to be important in curtailing $\mathrm{T}_{\mathrm{FH}}$ cell help for GC B cells ${ }^{136}$. It is possible CTLA4 may also have a role in promoting the function or development of follicular regulatory $\mathrm{T}$ cells.

Role of GC checkpoints in human B cell tolerance As discussed above, the role of SHM and antigen-driven affinity maturation is well established in mouse and human autoimmunity suggesting that tolerance mechanisms in the GCs are defective. However, the actual contribution of defective GC-based checkpoints to the generation of disease-associated autoantibodies is even more difficult to establish in humans than in mice. This is because of experimental limitations including access to human secondary lymphoid tissue and intrinsic differences between B cell responses in humans and mice. However, different human autoantibody responses exhibit characteristics that suggest they arise through fundamentally different mechanisms. These include structural differences: some forms of autoimmune haemolytic anaemia are associated with unmutated IgM isotype autoantibodies specific for erythrocyte antigens, whereas SLE is associated with high affinity, somatically mutated DNA-specific antibodies. Furthermore, the serum concentration of some autoantibodies varies with disease activity and treatment (for example double-stranded DNA-specific antibodies and PR3-specific antibodies), whereas other autoantibody titres (such as those specific for the extractable nuclear antigens Ro, $\mathrm{La}$ and $\mathrm{Sm}$ ) are remarkably stable even during disease remission. This interesting dichotomy has been recently highlighted by the differential autoantibody response observed in patients treated with rituximab, which depletes $\mathrm{CD} 20^{+} \mathrm{B}$ cells and most plasmablasts (presumably through the elimination of precursor B cells) but not long-lived plasma cells ${ }^{137}$.

A likely role for abnormal GC reactions in the pathogenesis of human autoimmune diseases is supported by multiple lines of evidence. Hyperactive GC reactions can be found in secondary lymphoid tissues in SLE and in targeted non-lymphoid tissues in multiple other autoimmune diseases. The observation that treatment with CD40L-specific antibody ameliorates disease, reduces autoantibody titres and decreases the number of peripheral blood B cells with a GC and postGC phenotype in some patients with SLE supports a possible follicular origin of autoantibodies, although this treatment is predicted to disrupt both GCs and extrafollicular T cell-dependent responses ${ }^{138,139}$. Similarly, it has been suggested that at least part of the therapeutic benefit of blockade of tumour necrosis factor in patients with rheumatoid arthritis could derive from the disruption of systemic GC and FDC networks induced by this agent ${ }^{140}$.

Moreover, GCs in patients with SLE are characterized by an accumulation of free apoptotic bodies that are readily accessible to GC B cells ${ }^{141}$. In a subgroup of patients with SLE, apoptotic cells accumulate, accompanied by a loss of tingible body macrophages, in the GCs of the lymph nodes ${ }^{142}$, and apoptotic material was observed to be directly associated with FDCs. Given the known ability of oxidized apoptotic bodies to induce pathogenic autoantibodies ${ }^{143}$, the recently described ability of human IgG autoantibodies specific for apoptotic bodies to induce pro-inflammatory cytokine production ${ }^{144}$ and the finding that autoantibodies bound to apoptotic glomerular cells in the kidneys of patients with SLE $^{145}$, it is tempting to postulate an important role for defective GCs in the censoring of autoreactive B cells in the pathogenesis of human SLE.

Few studies have specifically addressed the function of GC-based tolerance checkpoints in humans. However, important information has been provided by single-cell studies of class-switched memory B cells in healthy subjects and patients with SLE ${ }^{17,146}$. These cells are typically thought to be derived from GCs in a T cell-dependent manner, although, as elegantly shown in recent work, class switching of human B cells can also be induced outside of the GCs in a BAFF-mediated, CD40Lindependent manner ${ }^{147,148}$. These studies have shown that SHM commonly generates autoreactive antibodies against nuclear antigens, as well as polyreactive antibodies with autoimmune potential, in a large fraction of all human IgG-producing memory B cells to a similar extent in both patients with SLE and the normal controls studied. One of the patients studied, however, showed a high frequency of heavily mutated Ro- and La-specific autoantibodies in the switched memory B cell compartment that was absent in healthy controls and other patients, indicating that disease-specific autoreactivity requires SHM, presumably selected in GCs.

Direct assessment of the role of GCs in censoring disease-associated autoreactive $\mathrm{B}$ cells has been provided by the study of autoreactive 9G4 B cells ${ }^{149,150}$. These cells are selectively expanded in patients with active SLE, with serum 9G4 titres associating with disease activity and the presence of glomerulonephritis. It has been shown that, despite the large frequency of 9G4 B cells in the naive B cell compartment, GCs in healthy individuals are competent in censoring these cells, which are virtually never found in mature GCs in healthy individuals ${ }^{149,150}$. By contrast, $\sim 25 \%$ of all GCs analysed using tonsil biopsies of patients with SLE contain proliferating (that is, Ki67+) expansions of the GC 9G4 B cell subset and an abundance of the corresponding class-switched memory B cells and plasma cells. Of interest, this defective GC censoring seems to be specific for SLE as it is not found in rheumatoid arthritis follicles. 
Higher than normal levels of circulating cells that resemble $\mathrm{T}_{\mathrm{FH}}$ cells (defined as circulating CXCR5 $5^{+} \mathrm{CD} 4^{+}$ cells with high expression of $\mathrm{T}_{\mathrm{FH}}$ cell-associated molecules such as ICOS and PD1) are found in a subset of patients with SLE but not controls ${ }^{151}$. This cellular phenotype did not vary with time, disease activity or treatment but did correlate with diversity and titre of autoantibodies and severity of end-organ involvement. Increased IL-17 and IL-21 have been reported in the serum of human patients with SLE ${ }^{151-153}$. These findings are consistent with the proposed disease mechanism in sanroque mice and identify $\mathrm{T}_{\mathrm{FH}}$ cell effector molecules as possible therapeutic targets in a recognizable subset of patients.

It is important to emphasize that most of the evidence cited in support of either a follicular or an extrafollicular origin for autoantibodies can be used to support the contrary position. We have mentioned evidence showing both pathogenic and protective roles for ectopic GCs, which questions the notion that ectopic GCs support a follicular origin of autoantibodies. Furthermore, the short-lived nature of autoantibody responses in mouse models and in humans with autoimmune disease (either as measured directly ${ }^{154,155}$ or as inferred by the rapid and selective loss of certain types of autoantibody after B cell depletion therapy ${ }^{137}$ ) has been regarded as evidence in support of an extrafollicular origin ${ }^{156}$. However, a correlation between the appearance of new $\mathrm{CD} 27^{+}$memory $B$ cells after the same therapy and disease recurrence has been cited as evidence of a follicular origin of autoantibodies ${ }^{157}$. Furthermore, the observation in mice ${ }^{155}$ and in humans ${ }^{158,159}$ that increases in the number of circulating plasmablasts coincide with disease remission in SLE could be interpreted to indicate either extrafollicular or GC activity given that most GC-derived B cells enter the circulation on their way to the bone marrow.

\section{Prospects}

Several cellular mechanisms are now available to explain long-standing and compelling molecular evidence for the GC origin of many autoantibodies. Autoimmunity of follicular origin poses a considerable challenge because once the long-lived autoreactive plasma cells or memory $B$ cells have been generated, treatments that disrupt GCs or FDCs, such as lymphotoxin- $\beta$ receptor chimeric antibody, or that fail to eliminate long-lived plasma cells, such as rituximab, might not always be successful. It is notable that autoantibodies can arise not only from defects in binary tolerance checkpoints but also from extended survival of GCs. Indeed, abnormalities of each of the cellular constituents of GCs, as well as antigen itself, affect GC survival and therefore autoantibody production. This is a key conceptual advance because it implies that a targeted therapy for autoimmunity would be effective if it were to 'tune down' the GCs in order to reduce the risk of autoimmunity while preserving foreign antigenspecific responses. By contrast, a therapy based on a binary tolerance checkpoint might be expected to block all GC functions. So far, several molecular targets are apparent (FIG. 2), and therapeutic agents are already available for some of these targets. The ultimate test of the significance of the GC origin for autoimmunity will come with the application of these agents in the clinic.
1. Primi, D., Hammarstrom, L., Smith, C. I. \& Moller, G. Characterization of self-reactive B cells by polyclonal B-cell activators. J. Exp. Med. 145, 21-30 (1977).

2. Wardemann, H. et al. Predominant autoantibody production by early human B cell precursors. Science 301, 1374-1377 (2003).

3. Dighiero, G. et al. High frequency of natura autoantibodies in normal newborn mice. J. Immunol. 134, 765-771 (1985).

4. Cote, R. J. et al. Specificity analysis of human monoclonal antibodies reactive with cell surface and intracellular antigens. Proc. Natl Acad. Sci. USA 83. 2959-2963 (1986).

5. Shlomchik, M. et al. Anti-DNA antibodies from autoimmune mice arise by clonal expansion and somatic mutation. J. Exp. Med. 171, 265-292 (1990).

6. Marion, T. N., Bothwell, A. L., Briles, D. E. \& Janeway, C. A. Jr. IgG anti-DNA autoantibodies within an individual autoimmune mouse are the products of clonal selection. J. Immunol. 142, 4269-4274 (1989).

7. Behar, S. M., Lustgarten, D. L., Corbet, S. \& Scharff, M. D. Characterization of somatically mutated S107 VH11-encoded anti-DNA autoantibodies derived from autoimmune (NZB x NZW)F1 mice. J. Exp. Med. 173, 731-741 (1991).

8. Allen, C. D., Okada, T. \& Cyster, J. G. Germinal-center organization and cellular dynamics. Immunity 27, 190-202 (2007)

9. MacLennan, I. C. \& Gray, D. Antigen-driven selection of virgin and memory B cells. Immunol. Rev. 91, 61-85 (1986).

An important summary of seminal studies of B cell responses to foreign antigens by the authors and their collaborators, as well as a prescient description of GC function.

10. Thorbecke, G. J. Some histological and functional aspects of lymphoid tissue in germfree animals. I. Morphological studies. Ann. NY Acad. Sci. 78 237-246 (1959)
11. Gearhart, P. J., Johnson, N. D., Douglas, R. \& Hood, L. IgG antibodies to phosphorylcholine exhibit more diversity than their IgM counterparts. Nature 291, 29-34 (1981).

12. Bothwell, A. L. et al. Heavy chain variable region contribution to the $\mathrm{NP}^{\mathrm{b}}$ family of antibodies: somatic mutation evident in a $\gamma 2$ a variable region. Cell 24 625-637 (1981).

13. Toellner, K. M. et al. Thelper 1 (Th1) and Th2 characteristics start to develop during $\mathrm{T}$ cell priming and are associated with an immediate ability to induce immunoglobulin class switching. J. Exp. Med. 187 1193-1204 (1998).

14. Karrer, U. et al. Antiviral B cell memory in the absence of mature follicular dendritic cell networks and classical germinal centers in TNFR 1 mice. J. Immunol. 164 768-778 (2000).

15. Matsumoto, M., Fu, Y. X., Molina, H. \& Chaplin, D. D. Lymphotoxin- $\alpha$-deficient and TNF receptor-l-deficient mice define developmental and functional characteristics of germinal centers. Immunol. Rev. 156, 137-144 (1997).

16. Ray, S. K., Putterman, C. \& Diamond, B. Pathogenic autoantibodies are routinely generated during the response to foreign antigen: a paradigm for autoimmune disease. Proc. Natl Acad. Sci. USA 93 2019-2024 (1996)

17. Tiller, T. et al. Autoreactivity in human $\operatorname{lgG}^{+}$memory B cells. Immunity 26, 205-213 (2007).

18. Tarlinton, D., Radbruch, A., Hiepe, F. \& Dorner, T Plasma cell differentiation and survival. Curr. Opin. Immunol. 20, 162-169 (2008).

19. Rose, N. R. ¿ Bona, C. Defining criteria for autoimmune diseases (Witebsky's postulates revisited). Immunol. Today 14, 426-430 (1993)

20. McHeyzer-Williams, M. G., McLean, M. J., Lalor, P. A. \& Nossal, G. J. Antigen-driven B cell differentiation in vivo. J. Exp. Med. 178, 295-307 (1993).

21. Diamond, B. \& Scharff, M. D. Somatic mutation of the T15 heavy chain gives rise to an antibody with autoantibody specificity. Proc. Natl Acad. Sci. USA 81 5841-5844 (1984).
This paper shows that protective antimicrobial antibodies can convert into pathogenic autoantibodies through single point mutations.

22. Jacobson, B. A., Rothstein, T. L. \& Marshak-Rothstein, A. Unique site of $\operatorname{lgG} 2 \mathrm{a}$ and rheumatoid factor production in MRL/Ipr mice. Immunol. Rev. 156 103-110 (1997).

23. William, J., Euler, C., Christensen, S. \& Shlomchik, M. J. Evolution of autoantibody responses via somatic hypermutation outside of germinal centers. Science 297, 2066-2070 (2002).

24. Mandik-Nayak, L. et al. MRL-Ipr/Ipr mice exhibit a defect in maintaining developmental arrest and follicular exclusion of anti-double-stranded DNA B cells. J. Exp. Med. 189, 1799-1814 (1999).

25. Eaton-Bassiri, A. S. et al. Alterations in splenic architecture and the localization of anti-doublestranded DNA B cells in aged mice. Int. Immunol. 12, 915-926 (2000).

26. Groom, J. R. et al. BAFF and MyD88 signals promote a lupuslike disease independent of T cells. J. Exp. Med 204, 1959-1971 (2007).

27. Tsao, P. Y., Jiao, J., Ji, M. Q., Cohen, P. L. \& Eisenberg, R. A. T cell-independent spontaneous loss of tolerance by anti-double-stranded DNA B cells in C57BL/6 mice. J. Immunol. 181, 7770-7777 (2008).

28. Fazilleau, N., Mark, L., McHeyzer-Williams, L. J. $\delta$ McHeyzer-Williams, M. G. Follicular helper T cells: lineage and location. Immunity 30, 324-335 (2009).

29. Pereira, J. P., Kelly, L. M., Xu, Y. \& Cyster, J. G EBI2 mediates B cell segregation between the outer and centre follicle. Nature 460, 1122-1126 (2009)

30. Gatto, D. Paus, D., Basten, A., Mackay, C. R. \& Brink, R. Guidance of B cells by the orphan $G$ protein-coupled receptor EBI2 shapes humoral immune responses. Immunity 31, 259-269 (2009).

31. Staudt, L. M., Dent, A. L., Shaffer, A. L. \& Yu, X. Regulation of lymphocyte cell fate decisions and lymphomagenesis by BCL-6. Int. Rev. Immunol. 18 , 381-403 (1999). 
32. Fazilleau, N., McHeyzer-Williams, L. J., Rosen, H. \& McHeyzer-Williams, M. G. The function of follicular helper T cells is regulated by the strength of $\mathrm{T}$ cell antigen receptor binding. Nature Immunol. 10, 375-384 (2009)

33. Schwartzberg, P. L., Mueller, K. L, Oi, H. \& Cannons, J. L. SLAM receptors and SAP influence lymphocyte interactions, development and function. Nature Rev. Immunol. 9, 39-46 (2009).

34. King, C. New insights into the development and function of T follicular helper cells. Nature Rev. Immunol. 9, 757-766 (2009).

35. Yu, D. et al. The transcriptional repressor $\mathrm{Bcl}-6$ directs $\mathrm{T}$ follicular helper lineage commitment. Immunity 31 457-468 (2009)

36. Allen, C. D. et al. Germinal center dark and light zone organization is mediated by CXCR4 and CXCR5. Nature Immunol. 5, 943-952 (2004).

37. Caron, G., Le Gallou, S., Lamy, T., Tarte, K. \& Fest, T. CXCR4 expression functionally discriminates centroblasts versus centrocytes within human germinal center B cells. J. Immunol. 182. 7595-7602 (2009).

38. Kosco-Vilbois, M. H. \& Scheidegger, D. Follicular dendritic cells: antigen retention, $\mathrm{B}$ cell activation, and cytokine production. Curr. Top. Microbiol. Immunol. 201, 69-82 (1995)

39. Hauser, A. E., Shlomchik, M. J. \& Haberman, A. M. In vivo imaging studies shed light on germinal-centre development. Nature Rev. Immunol. 7, 499-504 (2007).

40. Tarlinton, D. B-cell memory: are subsets necessary? Nature Rev. Immunol. 6, 785-790 (2006).

41. Delgado, P. et al. Essential function for the GTPase TC21 in homeostatic antigen receptor signaling. Nature Immunol. 10, 880-888 (2009).

42. Koopman, G. et al. Adhesion through the LFA-1 (CD 11a/CD18)-ICAM-1 (CD54) and the VLA-4 (CD49d)-VCAM-1 (CD106) pathways prevents apoptosis of germinal center B cells. J. Immunol. 152, 3760-3767 (1994)

43. Carrasco, Y. R., Fleire, S. J., Cameron, T., Dustin, M. L. $\&$ Batista, F. D. LFA-1/ICAM-1 interaction lowers the threshold of B cell activation by facilitating B cell adhesion and synapse formation. Immunity 20 589-599 (2004).

44. Randall, K. et al. DOCK8 mutations cripple B cell immune synapse, germinal centers and long-lived antibody production. Nature Immunol. 8 Nov 2009 (doi: 10.1038/ni1820)

45. Vinuesa, C. G., Tangye, S. G., Moser, B. \& Mackay, C. R. Follicular B helper T cells in antibody responses and autoimmunity. Nature Rev. Immunol. 5, 853-865 (2005).

46. Takahashi, Y., Ohta, H. \& Takemori, T. Fas is required for clonal selection in germinal centers and the subsequent establishment of the memory B cell repertoire. Immunity 14, 181-192 (2001).

47. Hao, Z. et al. Fas receptor expression in germinalcenter $B$ cells is essential for $T$ and $B$ lymphocyte homeostasis. Immunity 29, 615-627 (2008)

48. Shlomchik, M. J., Marshak-Rothstein, A. Wolfowicz, C. B., Rothstein, T. L. \& Weigert, M. G. The role of clonal selection and somatic mutation in autoimmunity. Nature 328, 805-811 (1987) The first demonstration that autoimmune disease-related autoantibodies are not simply the product of generalized polyclonal B cell activation. Instead, similar to responses induced by exogenous immunizations, rheumatoid factor autoantibodies are shown to be the product of somatically mutated, antigen-selected oligoclonal B cells.

49. Olee, T et al. Genetic analysis of self-associating immunoglobulin $\mathrm{G}$ rheumatoid factors from two rheumatoid synovia implicates an antigen-driven response. J. Exp. Med. 175, 831-842 (1992).

50. McIntosh, R. S., Asghar, M. S., Watson, P. F., Kemp, E. H. \& Weetman, A. P. Cloning and analysis of IgG kappa and IgG lambda anti-thyroglobulin autoantibodies from a patient with Hashimoto's thyroiditis: evidence for in vivo antigen-driven repertoire selection. J. Immunol. 157, 927-935 (1996).

51. Hershberg, U., Uduman, M., Shlomchik, M. J. \& Kleinstein, S. H. Improved methods for detecting selection by mutation analysis of $\mathrm{Ig} \mathrm{V}$ region sequences. Int. Immunol. 20, 683-694 (2008).

52. Neeli, I. et al. Divergent members of a single autoreactive $B$ cell clone retain specificity for apoptotic blebs. Mol. Immunol. 44, 1914-1921 (2007).

53. Wellmann, U. et al. The evolution of human antidouble-stranded DNA autoantibodies. Proc. Natl Acad. Sci. USA 102, 9258-9263 (2005).
54. Luzina, I. G et al. Spontaneous formation of germinal centers in autoimmune mice. J. Leukoc. Biol. 70 578-584 (2001). A comprehensive histological survey of mouse strains that are prone to SLE-like disease.

55. Victoratos, P. \& Kollias, G. Induction of autoantibodymediated spontaneous arthritis critically depends on follicular dendritic cells. Immunity 30, 130-142 (2009).

56. Aloisi, F. \& Pujol-Borrell, R. Lymphoid neogenesis in chronic inflammatory diseases. Nature Rev. Immunol. 6, 205-217 (2006)

57. Cantaert, T. et al. B lymphocyte autoimmunity in rheumatoid synovitis is independent of ectopic lymphoid neogenesis. J. Immunol. 181, 785-794 (2008).

58. Anolik, J. H. et al. Delayed memory B cell recovery in peripheral blood and lymphoid tissue in systemic lupus erythematosus after $\mathrm{B}$ cell depletion therapy. Arthritis Rheum. 56, 3044-3056 (2007).

59. Anolik, J. H. et al. Restoration of proper germinal center regulation of autoreactive $B$ cells in human SLE after B cell depletion therapy. Arthritis Rheum. 54, S806 (2006).

60. Weyand C. M., Kurtin, P. J. \& Goronzy, J. J. Ectopic lymphoid organogenesis: a fast track for autoimmunity. Am. J. Pathol. 159, 787-793 (2001)

61. Armengol, M. P. et al. Thyroid autoimmune disease: demonstration of thyroid antigen-specific B cells and recombination-activating gene expression in chemokine-containing active intrathyroidal germinal centers. Am. J. Pathol. 159, 861-873 (2001).

62. Stott, D. I., Hiepe, F., Hummel, M., Steinhauser, G. \& Berek, C. Antigen-driven clonal proliferation of B cells within the target tissue of an autoimmune disease. The salivary glands of patients with Sjogren's syndrome. J. Clin. Invest. 102, 938-946 (1998).

63. Salomonsson, S. et al. Cellular basis of ectopic germina center formation and autoantibody production in the target organ of patients with Sjogren's syndrome. Arthritis Rheum. 48, 3187-3201 (2003).

64. Humby, F. et al. Ectopic lymphoid structures support ongoing production of class-switched autoantibodies in rheumatoid synovium. PLoS Med. 6, e 1 (2009).

65. Meyer, O. et al. Serial determination of cyclic citrullinated peptide autoantibodies predicted five-year radiological outcomes in a prospective cohort of patients with early rheumatoid arthritis. Arthritis Res. Ther. 8, R40 (2006)

66. Herlands, R. A., Christensen, S. R., Sweet, R. A., Hershberg, U. ¿ Shlomchik, M. J. T cell-independent and toll-like receptor-dependent antigen-driven activation of autoreactive B cells. Immunity 29 249-260 (2008).

67. Christensen, S. R. et al. Toll-like receptor 7 and TLR9 dictate autoantibody specificity and have opposing inflammatory and regulatory roles in a murine mode of lupus. Immunity 25, 417-428 (2006).

68. Eckl-Dorna, J. \& Batista, F. D. BCR-mediated uptake of antigen linked to TLR9 ligand stimulates B-cell proliferation and antigen-specific plasma cell formation. Blood 113, 3969-3977 (2009)

69. Bubier, J. A. et al. A critical role for IL-21 recepto signaling in the pathogenesis of systemic lupus erythematosus in BXSB-Yaa mice. Proc. Natl Acad. Sci. USA 106, 1518-1523 (2009).

70. Adelstein, S. et al. Induction of self-tolerance in T cells but not B cells of transgenic mice expressing little self antigen. Science 251, 1223-1225 (1991).

71. Fulcher, D. A. et al. The fate of self-reactive B cells depends primarily on the degree of antigen receptor engagement and availability of T cell help. J. Exp. Med. 183, 2313-2328 (1996)

72. Cook, M. C., Basten, A. \& Fazekas de St. Groth, B. Outer periarteriolar lymphoid sheath arrest and subsequent differentiation of both naive and tolerant immunoglobulin transgenic B cells is determined by B cell receptor occupancy. J. Exp. Med. 186, 631-643 (1997).

73. Lesley, R. et al. Reduced competitiveness of autoantigen-engaged $B$ cells due to increased dependence on BAFF. Immunity 20, 441-453 (2004).

74 Ang, C. W., Jacobs, B. C. \& Laman, J. D. The GuillainBarre syndrome: a true case of molecular mimicry. Trends Immunol. 25, 61-66 (2004).

75. Meyer-Bahlburg, A. \& Rawlings, D. J. B cell autonomous TLR signaling and autoimmunity. Autoimmun. Rev. 7, 313-316 (2008).

76. Leadbetter, E. A. et al. Chromatin-IgG complexes activate $B$ cells by dual engagement of IgM and Toll-like receptors. Nature 416, 603-607 (2002).

77. Lau, C. M. et al. RNA-associated autoantigens activate $B$ cells by combined B cell antigen receptor Toll-like receptor 7 engagement. J. Exp. Med. 202, 1171-1177 (2005).
78. Barrat, F. J. et al. Nucleic acids of mammalian origin can act as endogenous ligands for Toll-like receptors and may promote systemic lupus erythematosus. J. Exp. Med. 202, 1131-1139 (2005)

79. Barr, T. A., Brown, S., Mastroeni, P. \& Gray, D. $\mathrm{B}$ cell intrinsic MyD88 signals drive IFN- $\gamma$ production from $\mathrm{T}$ cells and control switching to $\lg \mathrm{G} 2 \mathrm{c}$. J. Immunol. 183, 1005-1012 (2009).

80. Meyer-Bahlburg, A., Khim., S. \& Rawlings, D. J. B cell intrinsic TLR signals amplify but are not required for humoral immunity. J. Exp. Med. 204, 3095-3101 (2007).

81. Kondo, E. \& Yoshino, T. Expression of apoptosis regulators in germinal centers and germinal centerderived B-cell lymphomas: insight into B-cell lymphomagenesis. Pathol. Int. 57, 391-397 (2007)

82 Smith, K. G et al. bcl-2 transgene expression inhibits apoptosis in the germinal center and reveals differences in the selection of memory B cells and bone marrow antibody-forming cells. J. Exp. Med. 191, 475-484 (2000).

83. Hande, S., Notidis, E. \& Manser, T. Bcl-2 obstructs negative selection of autoreactive, hypermutated antibody $\mathrm{V}$ regions during memory $\mathrm{B}$ cell development. Immunity 8, 189-198 (1998).

84. Takahashi, Y. et al. Relaxed negative selection in germinal centers and impaired affinity maturation in bcl- $x_{L}$ transgenic mice. J. Exp. Med. 190, 399-410 (1999).

85. Fischer, S. F. et al. Proapoptotic BH3-only protein Bim is essential for developmentally programmed death of germinal center-derived memory B cells and antibodyforming cells. Blood 110, 3978-3984 (2007).

References 83-85, together with reference 55 , illustrate how GC B cell survival is limited through controlled expression of BCL-2 family members to prevent the selection of B cells with autoreactive BCRs.

86. Blatt, N. B. et al. Benzodiazepine-induced superoxide signals B cell apoptosis: mechanistic insight and potential therapeutic utility. J. Clin. Invest. 110 1123-1132 (2002)

87. Rahman, Z. S. et al. Expression of the autoimmune Fcgr $2 b$ NZW allele fails to be upregulated in germina center $\mathrm{B}$ cells and is associated with increased IgC production. Genes Immun. 8, 604-612 (2007).

88. Jiang, Y. et al. Genetically determined aberrant downregulation of $\mathrm{Fc} \gamma \mathrm{RIIB} 1$ in germinal center $\mathrm{B}$ cells associated with hyper-lgG and IgG autoantibodies in murine systemic lupus erythematosus. Int. Immunol. 11, 1685-1691 (1999)

89. Mackay, M. et al. Selective dysregulation of the FcyllB receptor on memory B cells in SLE. J. Exp. Med. 203, 2157-2164 (2006)

90. Su, K. et al. Expression profile of FcyRllb on leukocytes and its dysregulation in systemic lupus erythematosus. J. Immunol. 178, 3272-3280 (2007).

91. Yuasa, T. et al. Deletion of Fcy receptor IIB renders $\mathrm{H}-2^{\mathrm{b}}$ mice susceptible to collagen-induced arthritis. J. Exp. Med. 189, 187-194 (1999).

92. Bolland, S. \& Ravetch, J. V. Spontaneous autoimmune disease in Fc $\gamma$ RIIB-deficient mice results from strainspecific epistasis. Immunity 13, 277-285 (2000).

93. Tsao, B. P. Lupus susceptibility genes on human chromosome 1. Int. Rev. Immunol. 19, 319-334 (2000).

94. McGaha, T. L., Sorrentino, B. \& Ravetch, J. V. Restoration of tolerance in lupus by targeted inhibitory receptor expression. Science 307 590-593 (2005).

95. Shokat, K. M. \& Goodnow, C. C. Antigen-induced B-cell death and elimination during germinal-centre immune responses. Nature 375, 334-338 (1995).

96. Pulendran, B., Kannourakis, G., Nouri, S., Smith, K. G. $\&$ Nossal, G. J. Soluble antigen can cause enhanced apoptosis of germinal-centre B cells. Nature 375 331-334 (1995)

97. Han, S., Zheng, B., Dal Porto, J. \& Kelsoe, G. In situ studies of the primary immune response to (4-hydroxy-3-nitrophenyl)acetyl. IV. Affinity-dependent, antigen-driven B cell apoptosis in germinal centers as mechanism for maintaining self-tolerance. J. Exp. Med. 182, 1635-1644 (1995). References 95-97 describe soluble-antigeninduced death of GC B cells, highlighting the need for accessory selection signals at the time of antigen encounter, presumably from FDCs.

98. Drayton, D. L., Liao, S., Mounzer, R. H. \& Ruddle, N. H. Lymphoid organ development: from ontogeny to neogenesis. Nature Immunol. 7, 344-353 (2006).

99. Ansel, K. M. et al. A chemokine-driven positive feedback loop organizes lymphoid follicles. Nature 406, 309-314 (2000). 
100. Douglas, K. B. et al. Complement receptor 2 polymorphisms associated with systemic lupus erythematosus modulate alternative splicing. Genes Immun. 10, 457-469 (2009).

101. Fliedner, T., Kesse, M., Cronkite, E. P. \& Robertson, J. S Cell proliferation in germinal centers of the rat spleen. Ann. NY Acad. Sci. 113, 578-594 (1964).

102. Casciola-Rosen, L. A., Anhalt, G. \& Rosen, A. Autoantigens targeted in systemic lupus erythematosus are clustered in two populations of surface structures on apoptotic keratinocytes. J. Exp. Med. 179 1317-1330 (1994).

This paper brought about a major conceptua advance in understanding the specificity of autoantibody responses in SLE and their relation to apoptosis.

103. Kranich, J. et al. Follicular dendritic cells control engulfment of apoptotic bodies by secreting Mfge8. J. Exp. Med. 205, 1293-1302 (2008).

104. Taylor, P. R. et al. A hierarchical role for classical pathway complement proteins in the clearance of apoptotic cells in vivo. J. Exp. Med. 192, 359-366 (2000).

105. Scott, R. S. et al. Phagocytosis and clearance of apoptotic cells is mediated by MER. Nature $\mathbf{4 1 1}$, 207-211 (2001)

106. Napirei, M. et al. Features of systemic lupus erythematosus in Dnase 1-deficient mice. Nature Genet 25, 177-181 (2000).

107. Toth, B. et al. Transglutaminase 2 is needed for the formation of an efficient phagocyte portal in macrophages engulfing apoptotic cells. J. Immunol. 182, 2084-2092 (2009)

108. Plotz, P. H. The autoantibody repertoire: searching for order. Nature Rev. Immunol. 3, 73-78 (2003).

109. Tomer, Y., Greenberg, D. A., Concepcion, E., Ban, Y. \& Davies, T. F. Thyroglobulin is a thyroid specific gene for the familial autoimmune thyroid diseases. J. Clin. Endocrinol. Metab. 87, 404-407 (2002).

110. Ban, Y. et al. Amino acid substitutions in the thyroglobulin gene are associated with susceptibility to human and murine autoimmune thyroid disease. Proc. Natl Acad. Sci. USA 100, 15119-15124 (2003).

111. Dechairo, B. M. et al. Association of the TSHR gene with Graves' disease: the first disease specific locus. Eur. J. Hum Genet. 13, 1223-1230 (2005).

112. Utz, P. J., Gensler, T. J. \& Anderson, P. Death, autoantigen modifications, and tolerance. Arthritis Res. 2, 101-114 (2000)

113. Marriq, C., Arnaud, C., Rolland, M. \& Lissitzky, S. An approach to the structure of thyroglobulin. Hormone-forming sequences in porcine thyroglobulin. Eur. J. Biochem. 111, 33-47 (1980).

114. Mizutori, Y., Chen, C. R., Latrofa, F., McLachlan, S. M. \& Rapoport, B. Evidence that shed thyrotropin receptor A subunits drive affinity maturation of autoantibodies causing Graves' disease. J. Clin. Endocrinol. Metab. 94 927-935 (2009)

115. Chazenbalk, G. D. et al. Thyroid-stimulating autoantibodies in Graves disease preferentially recognize the free A subunit, not the thyrotropin holoreceptor. J. Clin. Invest. 110, 209-217 (2002).

116. Giraud, M. et al. Genetic control of autoantibody expression in autoimmune myasthenia gravis: role of the self-antigen and of HLA-linked loci. Genes Immun 5, 398-404 (2004)

117. Kearney, E. R., Pape, K. A., Loh, D. Y. \& Jenkins, M. K. Visualization of peptide-specific T cell immunity and peripheral tolerance induction in vivo. Immunity 1, 327-339 (1994).

118. Meyer-Hermann, M. E., Maini, P. K. \& Iber, D. An analysis of $B$ cell selection mechanisms in germinal centers. Math. Med. Biol. 23, 255-277 (2006).

119. Brocker, T. et al. CD4 T cell traffic control: in vivo evidence that ligation of OX40 on CD4 T cells by OX40-ligand expressed on dendritic cells leads to the accumulation of CD4 T cells in B follicles. Eur. J. Immunol. 29, 1610-1616 (1999)

120. Murata, K. et al. Constitutive OX40/OX40 ligand interaction induces autoimmune-like diseases. J. Immunol. 169, 4628-4636 (2002)

121. Vinuesa, C. G. et al. A novel RING-type ubiquitin ligase family member essential to repress follicular helper $\mathrm{T}$ cells and autoimmunity. Nature $435,452-458$ (2005).

122. Subramanian, S. et al. A TIr7 translocation accelerates systemic autoimmunity in murine lupus. Proc. Nat Acad. Sci. USA 103, 9970-9975 (2006)

123. Linterman, M. et al. Follicular helper T cells are required for systemic autoimmunity J. Exp. Med. 206 561-576 (2009)

The first paper to highlight that aberrant positive selection can lead to autoimmunity, showing that excessive accumulation of $\mathrm{T}_{\mathrm{FH}}$ cells due to homozygosity for Roquin ${ }^{\text {san/san }}$ supports the formation of spontaneous GCs, double-stranded DNA-specific autoantibodies and end-organ tissue damage.

124. Takahashi, T. et al. Generalized lymphoproliferative disease in mice, caused by a point mutation in the Fas ligand. Cell 76, 969-976 (1994).

125. Watanabe-Fukunaga, R., Brannan, C. I., Copeland, N. G., Jenkins, N. A. \& Nagata, S. Lymphoproliferation disorder in mice explained by defects in Fas antigen that mediates apoptosis. Nature 356, 314-317 (1992).

126. Shlomchik, M. J., Madaio, M. P., Ni, D., Trounstein, M. $\Sigma$ Huszar, D. The role of B cells in Ipr/lpr-induced autoimmunity. J. Exp. Med. 180, 1295-1306 (1994).

127. Alabyev, B., Vuyyuru, R. \& Manser, T. Influence of Fas on the regulation of the response of an anti-nuclear antigen $\mathrm{B}$ cell clonotype to foreign antigen. Int Immunol. 20, 1279-1287 (2008).

128. Hsu, H. C. et al. Interleukin 17-producing T helper cells and interleukin 17 orchestrate autoreactive germinal center development in autoimmune BXD2 mice. Nature Immunol. 9, 166-175 (2008).

129. Tarlinton, D. IL-17 drives germinal center B cells? Nature Immunol. 9, 124-126 (2008).

130. Wu, H. Y., Quintana, F. J. \& Weiner, H. L. Nasal antiCD3 antibody ameliorates lupus by inducing an IL-10-secreting CD4 ${ }^{+} \mathrm{CD} 25^{-} \mathrm{LAP}^{+}$regulatory $\mathrm{T}$ cell and is associated with down-regulation of IL-17+ ${ }^{+} D 4^{+}$ ICOS+ CXCR5+ follicular helper T cells. J. Immunol. $181,6038-6050$ (2008)

131. Fairhurst, A. M. et al. Yaa autoimmune phenotypes are conferred by overexpression of TLR7. Eur. J. Immunol. 38, 1971-1978 (2008).

132. Pisitkun, P. et al. Autoreactive B cell responses to RNA-related antigens due to TLR7 gene duplication. Science 312, 1669-1672 (2006)

133. Odegard, J. M. et al. ICOS-dependent extrafollicular helper T cells elicit IgG production via IL-21 in systemic autoimmunity. J. Exp. Med. 205, 2873-2886 (2008).

134. Chan, T. D. et al. Antigen affinity controls rapid T-dependent antibody production by driving the expansion rather than the differentiation or extrafollicular migration of early plasmablasts. J. Immunol. 183, 3139-3149 (2009).

135. Lim, H., Hillsamer, P. \& Kim, C. H. Regulatory T cells can migrate to follicles upon $\mathrm{T}$ cell activation and suppress GC-Th cells and GC-Th cell-driven B cell responses. J. Clin. Invest. 114, 1640-1649 (2004).

136. Walker, L. S. et al. Established T cell-driven germinal center $\mathrm{B}$ cell proliferation is independent of CD28 signaling but is tightly regulated through CTLA-4. J. Immunol. 170, 91-98 (2003).

137. Cambridge, G. et al. Serologic changes following B lymphocyte depletion therapy for rheumatoid arthritis. Arthritis Rheum. 48, 2146-2154 (2003).

138. Grammer, A. C. et al. Abnormal germinal center reactions in systemic lupus erythematosus demonstrated by blockade of CD154-CD40 interactions. J. Clin. Invest. 112, 1506-1520 (2003).

139. Huang, W. et al. The effect of anti-CD40 ligand antibody on B cells in human systemic lupus erythematosus. Arthritis Rheum. 46, 1554-1562 (2002).

140. Anolik, J. H. et al. Cutting edge: anti-tumor necrosis factor therapy in rheumatoid arthritis inhibits memor $B$ lymphocytes via effects on lymphoid germinal centers and follicular dendritic cell networks. J. Immunol. 180 688-692 (2008)

141. Gaipl, U. S. et al. Clearance of apoptotic cells in human SLE. Curr. Dir Autoimmun 9, 173-187 (2006)

142. Baumann, I. et al. Impaired uptake of apoptotic cells into tingible body macrophages in germinal centers of patients with systemic lupus erythematosus. Arthritis Rheum. 46, 191-201 (2002).

References 105, 106 and 142 extend the findings of reference 102, proving that inefficient disposa of apoptotic cells can be immunogenic.

143. Chang, M. K. et al. Apoptotic cells with oxidationspecific epitopes are immunogenic and proinflammatory. J. Exp. Med. 200, 1359-1370 (2004)

144. Munoz, L. E. et al. Remnants of secondarily necrotic cells fuel inflammation in systemic lupus erythematosus. Arthritis Rheum. 60, 1733-1742 (2009)

145. Kalaaji, M., Mortensen, E., Jorgensen, L., Olsen, R. \& Rekvig, O. P. Nephritogenic lupus antibodies recognize glomerular basement membrane-associated chromatin fragments released from apoptotic intraglomerular cells. Am. J. Pathol. 168, 1779-1792 (2006)

146. Mietzner, B. et al. Autoreactive IgG memory antibodies in patients with systemic lupus erythematosus arise from nonreactive and polyreactive precursors. Proc. Natl Acad. Sci. USA 105, 9727-9732 (2008).

147. Litinskiy, M. B. et al. DCs induce CD40-independent immunoglobulin class switching through BLyS and APRIL. Nature Immunol. 3, 822-829 (2002).

148. Shlomchik, M. J. Sites and stages of autoreactive B cell activation and regulation. Immunity 28, 18-28 (2008)

149. Cappione, A., 3rd. et al. Germinal center exclusion of autoreactive $B$ cells is defective in human systemic lupus erythematosus. J. Clin. Invest. 115, 3205-3216 (2005).

The first direct analysis of the fate of human SLE-associated B cells in the GCs of healthy subjects and subjects with other autoimmune diseases. Autoreactive 9G4 B cells were found to be strictly censored in GCs from normal tonsils. By contrast, this censoring is defective in SLE but not in other autoimmune diseases, including rheumatoid arthritis.

150. Pugh-Bernard, A. E. et al. Regulation of inherently autoreactive VH4-34 B cells in the maintenance of human B cell tolerance. J. Clin. Invest. 108, 1061-1070 (2001)

151. Simpson, N. et al. Expansion of circulating T cells resembling $\mathrm{T}_{\mathrm{FH}}$ cells is a fixed phenotype that identifies a subset of severe systemic lupus erythematosus. Arthritis Rheum. (In the press).

This work shows that a subset of patients with SLE have expanded CXCR5 ${ }^{+} \mathrm{PD} 11^{\text {hil }} \mathrm{CO} \mathrm{S}^{\text {hi }} \mathrm{CD} 4^{+}$cells in the blood, suggestive of a dysregulated $\mathrm{T}_{\mathrm{FH}}$ cell pathway, and this cellular phenotype correlates with disease severity.

152. Wong, C. K., Ho, C. Y., Li, E. K. \& Lam, C. W. Elevation of proinflammatory cytokine (IL-18, IL-17, IL-12) and Th2 cytokine (IL-4) concentrations in patients with systemic lupus erythematosus. Lupus 9, 589-593 (2000).

153. Doreau, A. et al. Interleukin 17 acts in synergy with $B$ cell-activating factor to influence B cell biology and the pathophysiology of systemic lupus erythematosus. Nature Immunol. 10, 778-785 (2009).

154. Hoyer, B. F. et al. Short-lived plasmablasts and longlived plasma cells contribute to chronic humoral autoimmunity in NZB/W mice. J. Exp. Med. 199 1577-1584 (2004)

155. William, J., Euler, C. \& Shlomchik, M. J. Short-lived plasmablasts dominate the early spontaneous rheumatoid factor response: differentiation pathways, hypermutating cell types, and affinity maturation outside the germinal center. J. Immunol. 174 6879-6887 (2005)

156. Ferraro, A. J., Drayson, M. T., Savage, C. O. \& MacLennan, I. C. Levels of autoantibodies, unlike antibodies to all extrinsic antigen groups, fall following B cell depletion with Rituximab. Eur. J. Immunol. 38 , 292-298 (2008)

157. Moller, B. et al. Class-switched B cells display response to therapeutic B-cell depletion in rheumatoid arthritis. Arthritis Res. Ther. 11, R62 (2009).

158. Jacobi, A. M. et al. Correlation between circulating CD27 $7^{\text {high }}$ plasma cells and disease activity in patients with systemic lupus erythematosus. Arthritis Rheum. 48, 1332-1342 (2003)

159. Arce, E. et al. Increased frequency of pre-germinal center B cells and plasma cell precursors in the blood of children with systemic lupus erythematosus. J. Immunol. 167, 2361-2369 (2001).

160. Mukundan. et al. PPAR- $\delta$ senses and orchestrates clearance of apoptotic cells to promote tolerance. Nature Med. 15, 1266-1272 (2009).

\section{Acknowledgements}

C.G.V. and M.C.C. are funded by the Australian National Health and Medical Research Council, and C.G.V. is a recipient of a Viertel Senior Medical Research Fellowship.

DATABASES

UniProtKB: http://www.uniprot.org

AID $\mid$ BCL-2 |BCL-6 | BCL-X |BLIMP1 |CCR7 |CD40L |CD45

CD95|CD95L|CR2 |CXCR4 |CXCR5 |DOCK8 |EBI2| ICAM1 ICOS | IL-4 | IL-21 |IRF8 |MFGE8 |MYD88|PD1 RGS13 |RGS16 |SAP|SPIB | IC21 | ILR7| ILR9|VCAM1

FURTHER INFORMATION

Carola G. Vinuesa's homepage: http://jcsmr.anu.edu.au/ org/imm/humimm/index.php

SUPPLEMENTARY INFORMATION

See online article: $\underline{\mathrm{S}}$ (table)

ALL LINKS ARE ACTIVE IN THE ONLINE PDF 